\title{
Redox Properties of Manganese-Containing Zirconia Solid Solution Catalysts Analyzed by In Situ UV-Vis Spectroscopy and Crystal Field Theory
}

\author{
S. I. Klokishner, ${ }^{\mathrm{a}, \mathrm{b}}$ O. Reu, ${ }^{\mathrm{a}, \mathrm{b}}$ C. E. Chan Thaw, ${ }^{\mathrm{a}}$ F. C. Jentoft, ${ }^{\mathrm{a}, \mathrm{c}}$ R. Schlögl ${ }^{\mathrm{a}}$ \\ ${ }^{a}$ Department of Inorganic Chemistry, Fritz Haber Institute of the Max Planck Society, Faradayweg 4-6, \\ 14195 Berlin, Germany \\ bermanent address: Institute of Applied Physics of the Academy of Sciences of Moldova, Academy Street 5, \\ 2028 Kishinev, Moldova \\ 'new address: Chemical, Biological, and Materials Engineering, University of Oklahoma, \\ 100 East Boyd Street, Norman, OK 73019-1004, USA
}

"Corresponding author: e-mail fcjentoft@ou.edu,

Received: 12 April 2011, Published Online: 27 May 2011, Published: 27 May 2011

\begin{abstract}
A The optical absorption spectra of manganese-promoted sulfated zirconia, a highly active alkane isomerization catalyst, were found to be characterized by oxygen-to-manganese charge transfer transitions at 300-320 nm and d-d transitions of manganese ions at $580 \mathrm{~nm}$ and $680 \mathrm{~nm}$. The latter were attributed to $\mathrm{Mn}^{4+}$ and $\mathrm{Mn}^{3+}$ ions, which are known to be incorporated in the zirconia lattice. The oxygen surroundings of these ions were modeled assuming a substitutional solid solution. The crystal field splittings, vibronic coupling constants and oscillator strengths for the manganese ions were calculated on the basis of a cluster model that considers the manganese center as a complex with the adjacent ions of the lattice as ligands. The ratio of $\mathrm{Mn}^{3+}$ to $\mathrm{Mn}^{4+}$ ions was identified using the spectra and the model; and the relative concentrations of $\mathrm{Mn}^{2+}, \mathrm{Mn}^{3+}$ and $\mathrm{Mn}^{4+}$ ions were determined with the help of the average valence known from X-ray absorption data in the literature. The redox behavior of the manganese-promoted sulfated zirconia in oxidizing and inert atmosphere was elucidated at temperatures ranging from 323 to $773 \mathrm{~K}$.
\end{abstract}

Keywords: manganese, zirconia, UV-vis spectroscopy, solid solution, crystal field theory

\section{Introduction}

Manganese is a component in a variety of solid catalysts. Mixed copper-manganese oxides serve as $\mathrm{CO}$ oxidation catalysts in breathing apparatus [1,2], and $\mathrm{MnO}_{2}$ is used as a catalyst for the hydration of nitriles to amides [3]. The addition of manganese and copper to titania results in catalysts for oxidation of ammonia to $\mathrm{N}_{2}$ [4], and addition of manganese to zirconia produces materials active in the total oxidation of hydrocarbons [5,6]. Manganese also functions as a promoter in sulfated zirconia catalysts, which are highly active for the skeletal isomerization of $n$-butane at low temperatures $[7,8]$.
Many manganese oxidation states are stable, and mixed valence manganese oxides such as $\mathrm{Mn}_{3} \mathrm{O}_{4}$ (hausmannite) exist. Thus, manganese in catalysts (and other materials) can assume various and also multiple valences. The valence may change with activation of the catalyst and with exposure to reaction conditions. In fact, in oxidation catalysis the ability of the active metal species to change valence is essential. The catalytic cycle then consists of reduction and reoxidation steps, and a mixture of valences may be encountered in an operating oxidation catalyst.

Skeletal isomerization of alkanes is typified as an acid-catalyzed reaction; and when the promoting effect of manganese on sulfated zirconia materials was discovered, 
no attention was paid to the valence of manganese. The increase in activity [7] was ascribed to stronger acidity of the material [7,9]. However, Wan et al. [10] and later also Song and Kydd [11] proposed that promoters of sulfated zirconia such as iron are redox initiators in $n$-butane isomerization, after detecting a beneficial effect of an oxidative pre-treatment on mixed iron-manganese promoted sulfated zirconia catalysts. If manganese activated $n$-butane via oxidation, it would have to be reduced during the isomerization reaction, but Jentoft et al. [12] found that reduction during operation did not always occur. Klose et al. [13] demonstrated that the presence of manganese or iron increases the oxidation potential of the sulfate, which had previously been shown to activate butane in an oxidative dehydrogenation step $[14,15]$. This result suggests indeed a more indirect role of manganese but leaves the question about its most active oxidation state as a promoter of sulfated zirconia unanswered. The maximum isomerization activity of manganese-promoted sulfated zirconia was found to increase with increasing average manganese valence after activation [12]. The valence is typically a noninteger number between 2 and 3 [12]; thus, multiple manganese species must be present in manganese-containing zirconia, as also detected by Valigi et al. [16].

Information on the manganese valence can be obtained by several means, for example through dissolution of the sample and titration; however, digestion is not always possible without altering the oxidation state and cannot be applied in situ. The manganese oxidation state can be determined by X-ray absorption spectroscopy. The position of the Mn K edge was shown to linearly depend on the average manganese oxidation state [17], and this method was applied by Jentoft et al. [12]; however, the fractions of the individual oxidation states in a mixed valence sample cannot be extracted. Electron paramagnetic resonance is a suitable method to identify some of the paramagnetic states of manganese such as $\mathrm{Mn}^{2+}$ [18], but conventional EPR fails with low spin complexes of $\mathrm{Mn}^{3+}$ [19] and sometimes even with $\mathrm{Mn}^{4+}$ complexes. X-ray photoelectron spectroscopy is another possibility to identify various manganese oxidation states if a high enough concentration of surface species is present. Unfortunately, the position of the Mn $2 p$ signal depends on the valence and on the coordination of the cation, and some oxidation states may not be distinguishable $[4,20,21]$. UV-visible spectroscopy has also been applied to identify the manganese valence in pure and mixed manganese oxides $[22,23,24]$ and in supported moieties [25], but many transitions of various manganese cations fall into the same spectral region, and assignments presented in the literature are not unambiguous (Table 1).

The goals of this work are the following: to establish a consistent assignment of the transitions in the optical spectra of manganese-containing materials with the help of a structural model of manganese ions in zirconia and calculation of their electronic transitions, and to apply these assignments to the interpretation of spectra of manganesepromoted sulfated zirconia during treatment in various
Table 1: Reported assignments of electronic transitions of manganese species

\begin{tabular}{|c|c|c|c|}
\hline wavelength $(\mathrm{nm})$ & \multicolumn{2}{|c|}{ transition (CT or d-d) } & material \\
\hline 255 & \multicolumn{2}{|c|}{$\mathrm{O}^{2-} \rightarrow \mathrm{Mn}^{2+}\left(T_{d}\right)$} & $\mathrm{Mn}_{3} \mathrm{O}_{4}$ \\
\hline 313 & $\mathrm{Mn}^{2+}$ & ${ }^{6} \mathrm{~A}_{1} \rightarrow{ }^{4} \mathrm{~T}_{1}$ & $\mathrm{Mn}(\mathrm{Ac})_{2} \cdot 4 \mathrm{H}_{2} \mathrm{O}$ \\
\hline 320 & \multicolumn{2}{|c|}{$\mathrm{O}^{2-} \rightarrow \mathrm{Mn}^{3+}\left(\mathrm{O}_{h}\right)$} & $\mathrm{Mn}_{3} \mathrm{O}_{4}$ \\
\hline 340 & $\mathrm{Mn}^{2+}$ & ${ }^{6} \mathrm{~A}_{1} \rightarrow{ }^{4} \mathrm{E}$ & $\mathrm{Mn}(\mathrm{Ac})_{2} \cdot 4 \mathrm{H}_{2} \mathrm{O}$ \\
\hline 363 & $\mathrm{Mn}^{2+}$ & ${ }^{6} \mathrm{~A}_{1} \rightarrow{ }^{4} \mathrm{~T}_{2}$ & $\mathrm{Mn}(\mathrm{Ac})_{2} \cdot 4 \mathrm{H}_{2} \mathrm{O}$ \\
\hline 370 & \multicolumn{2}{|c|}{$\mathrm{O}^{2-} \rightarrow \mathrm{Mn}^{3+}\left(\mathrm{O}_{h}\right)$} & $\mathrm{Mn}_{2} \mathrm{O}_{3}$ \\
\hline 370 & \multicolumn{2}{|c|}{$\mathrm{O}^{2-} \rightarrow \mathrm{Mn}^{4+}$ or $\mathrm{d}-\mathrm{d}$ of $\mathrm{Mn}^{4+}$} & $\mathrm{Mn} / \mathrm{ZrO}_{2}$ \\
\hline 404 & $\mathrm{Mn}^{2+}$ & ${ }^{6} \mathrm{~A}_{1} \rightarrow{ }^{4} \mathrm{~A}_{1},{ }^{4} \mathrm{E}$ & $\mathrm{Mn}(\mathrm{Ac})_{2} \cdot 4 \mathrm{H}_{2} \mathrm{O}$ \\
\hline 420 & $\mathrm{Mn}^{2+}$ (cubic) & ${ }^{6} \mathrm{~A}_{1} \rightarrow{ }^{4} \mathrm{~A}_{1},{ }^{4} \mathrm{E}$ & $\mathrm{MnO}$ \\
\hline 422 & $\mathrm{Mn}^{2+}$ & ${ }^{6} \mathrm{~A}_{1} \rightarrow{ }^{4} \mathrm{~A}_{1}$ & $\mathrm{Mn} / \mathrm{Al}_{2} \mathrm{O}_{3}$ \\
\hline 440 & $\mathrm{Mn}^{2+}$ & ${ }^{6} \mathrm{~A}_{1} \rightarrow{ }^{4} \mathrm{~T}_{2}$ & $\mathrm{Mn}(\mathrm{Ac})_{2} \cdot 4 \mathrm{H}_{2} \mathrm{O}$ \\
\hline \multirow[t]{2}{*}{$444-500$} & $\mathrm{Mn}^{3+}$ & ${ }^{5} \mathrm{E}_{\mathrm{g}} \rightarrow{ }^{5} \mathrm{~T}_{2 \mathrm{~g}}$ & $\mathrm{Mn} / \mathrm{Al}_{2} \mathrm{O}_{3}$ \\
\hline & \multicolumn{3}{|l|}{$\mathrm{Mn}^{4+}$} \\
\hline 469 & $\mathrm{Mn}^{4+}$ & ${ }^{4} \mathrm{~A}_{2} \rightarrow{ }^{4} \mathrm{~T}_{2}$ & $\mathrm{Mn} / \mathrm{Al}_{2} \mathrm{O}_{3}$ \\
\hline 476 & $\mathrm{Mn}^{3+}$ & $a$ & $\mathrm{CsMn}\left(\mathrm{SO}_{4}\right) \cdot 12 \mathrm{H}_{2} \mathrm{O}$ \\
\hline 480 & $\mathrm{Mn}^{2+}$ (cubic) & ${ }^{6} \mathrm{~A}_{1} \rightarrow{ }^{4} \mathrm{~F}_{2}$ & $\mathrm{MnO}$ \\
\hline 485 & $\mathrm{Mn}^{3+}$ & $a$ & $\mathrm{Mn} / \mathrm{Al}_{2} \mathrm{O}_{3}$ \\
\hline 485 & $\mathrm{Mn}^{3+}\left(O_{h}\right)$ & ${ }^{5} B_{1 g} \rightarrow{ }^{5} B_{2 g}$ & $\mathrm{Mn}_{2} \mathrm{O}_{3}$ \\
\hline 490 & \multicolumn{2}{|l|}{$\mathrm{Mn}^{3+}\left(O_{h}\right)$} & Mn-APO-34 \\
\hline 500 & \multicolumn{2}{|l|}{$\mathrm{Mn}^{3+}$} & {$\left[\mathrm{Mn}\left(\mathrm{H}_{2} \mathrm{O}\right)_{6}\right]^{3+}$} \\
\hline 500 & \multicolumn{2}{|l|}{$\mathrm{Mn}^{3+}$ of $\mathrm{Mn}_{2} \mathrm{O}_{3}$} & $\mathrm{Mn} / \mathrm{ZrO}_{2}$ \\
\hline 535 & $\mathrm{Mn}^{3+}-\mathrm{C}^{3+}$ & $a$ & $\mathrm{Mn} / \mathrm{Al}_{2} \mathrm{O}_{3}$ \\
\hline$\$ 41$ & $\mathrm{Mn}^{2+}$ & ${ }^{6} \mathrm{~A}_{1} \rightarrow{ }^{4} \mathrm{~T}_{1}$ & $\mathrm{Mn}(\mathrm{Ac})_{2} \cdot 4 \mathrm{H}_{2} \mathrm{O}$ \\
\hline 565 & $\mathrm{Mn}^{2+}\left(T_{d}\right.$ or $\left.O^{*}\right)$ & ${ }^{6} \mathrm{~A}_{1} \rightarrow{ }^{4} \mathrm{~T}_{1}$ & $\mathrm{Mn}^{2+} / \mathrm{TiO}_{2}$ \\
\hline 610 & $\mathrm{Mn}^{2+}(\mathrm{cubic})$ & ${ }^{6} \mathrm{~A}_{1} \rightarrow{ }^{4} \mathrm{~F}_{1}$ & $\mathrm{MnO}$ \\
\hline 625 & $\mathrm{Mn}^{4+}$ & ${ }^{4} \mathrm{~A}_{1} \rightarrow{ }^{4} \mathrm{~T}_{1}$ & $\mathrm{Mn} / \mathrm{TiO}_{2}$ \\
\hline 740 & $\mathrm{Mn}^{3+}$ of $\mathrm{Mn}_{2} \mathrm{O}_{3}$ & & $\mathrm{Mn} / \mathrm{ZrO}_{2}$ \\
\hline 755 & $\mathrm{Mn}^{3+}\left(O_{h}\right)$ & ${ }^{5} \mathrm{~B}_{1 \mathrm{~g}} \rightarrow{ }^{5} \mathrm{~A}_{1 \mathrm{~g}}$ & $\mathrm{Mn}_{2} \mathrm{O}_{3}$ \\
\hline 900 & $\mathrm{Mn}^{3+}$ of $\mathrm{Mn}_{2} \mathrm{O}_{3}$ & & $\mathrm{Mn} / \mathrm{ZrO}_{2}$ \\
\hline 1750 & $\mathrm{Mn}^{3+}\left(\mathrm{O}_{h}\right)$ & ${ }^{5} \mathrm{E} \rightarrow{ }^{5} \mathrm{~T}_{2}$ & $\mathrm{Mn}_{3} \mathrm{O}_{4}$ \\
\hline
\end{tabular}

${ }^{a}$ See text for transition.

conditions. A key for the development of the model is the fact that manganese forms solid solutions with zirconia [16,33-36]. Earlier work showed that manganesepromoted sulfated zirconia catalysts contain such solid solutions [36], and we assume that the manganese ions are in a defined geometry in the zirconia lattice.

\section{Experimental}

\section{1. Sample preparation}

Manganese-promoted sulfated zirconia "MnSZ" with a manganese content of 0.5 or $2.0 \mathrm{wt} \%$ (metal) was prepared according to the incipient wetness method as previously described [37]. Sulfated hydrous zirconia (XZO 682/01, MEL Chemicals) was dried at $383 \mathrm{~K}$ for $21 \mathrm{~h}$ and cooled in a desiccator. A solution of $\mathrm{Mn}\left(\mathrm{NO}_{3}\right)_{2}$ (Merck) was added drop-wise to the powder under vigorous stirring. After drying at room temperature the raw material was calcined in portions of $20-25 \mathrm{~g}$ in a quartz boat, which was placed in a $29 \mathrm{~mm}$ I.D. quartz tube. The tube was purged 
with $200 \mathrm{~mL} \mathrm{~min}^{-1}$ synthetic air and heated in an oven at 3 $\mathrm{K} \min ^{-1}$ to $923 \mathrm{~K}$, held at this temperature for $3 \mathrm{~h}$, and cooled.

\subsection{UV-vis-NIR spectroscopy}

A PerkinElmer Lambda 950 spectrometer equipped with a Harrick Praying Mantis ${ }^{\text {TM }}$ DRP-P72 diffuse reflectance accessory and a HVC-VUV reaction chamber was used to record UV-vis-NIR spectra of MnSZ during various treatments. The spectroscopic measurements were carried out in the range of 250-2500 nm with a scan speed of $225 \mathrm{~nm} \mathrm{~min}{ }^{-1}$. The slit width was $2.5 \mathrm{~nm}$ in the UV-vis and $2 \mathrm{~nm}$ in the NIR range, the response time was $0.2 \mathrm{~s}$, and the reference beam was attenuated to $10 \%$. The reflectance $\rho(\lambda)$ of the sample was measured relative to a white standard, Spectralon ${ }^{\circledR}$ (Labsphere). A background correction ("Autozero") was performed with a small disk of this standard in the reaction chamber.

Approximately $200 \mathrm{mg}$ of catalyst were loaded into the reaction chamber. The powder was placed on a wire mesh and the gases were streamed through this fixed bed in down-flow operation. Pure helium or $\mathrm{O}_{2}$ (both $99.999 \%$ purity from Westfalen) were used for treatments in inert or oxidizing atmosphere, at flows of $20 \mathrm{~mL} \mathrm{~min}^{-1}(\mathrm{He})$ or 40 $\mathrm{mL} \min ^{-1}\left(\mathrm{O}_{2}\right)$. A spectrum was recorded at $323 \mathrm{~K}$ and then the temperature was raised to $773 \mathrm{~K}(\mathrm{He})$ or $823 \mathrm{~K}\left(\mathrm{O}_{2}\right)$ at a rate of $5 \mathrm{~K} \mathrm{~min}^{-1}$ while spectra were continuously acquired. To present and analyze the spectra, the Kubelka-Munk function $F(\rho)=(1-\rho)^{2} /(2 \rho)$ was calculated from the reflectance $\rho$.

\section{Results and qualitative interpretation of spectra}

Spectra were recorded during a typical activation procedure as it would be applied prior to isomerization catalysis. MnSZ (2wt\% Mn) was heated in helium flow from a temperature of $323 \mathrm{~K}$ to $773 \mathrm{~K}$ and then held at 773 $\mathrm{K}$ for $30 \mathrm{~min}$. The apparent absorption spectra of this material, obtained by converting the reflectance into the Kubelka-Munk function, are shown in Fig. 1. Interpretation of these spectra is facilitated by the knowledge that the average valence of manganese in the calcined catalysts is about $2.70 \pm 0.05$ [12]. Moreover, $\mathrm{Zr}^{4+}$ is not easily reduced, and no significant contributions from $\mathrm{Zr}^{3+} \mathrm{d}-\mathrm{d}$ transitions are expected. The band gap of $\mathrm{ZrO}_{2}$ has been reported to be between 250-285 nm [38-40] and accounts for the increasing absorbance below $300 \mathrm{~nm}$. Absorptions of sulfur(VI)oxygen surface species can be excluded; electronic transitions in $\mathrm{SO}_{3}$ and $\mathrm{H}_{2} \mathrm{SO}_{4}$ occur at wavelengths shorter than $200 \mathrm{~nm}$ [41]. The three observed bands in the range $300-1000 \mathrm{~nm}$ are thus likely to be associated with manganese species. Two bands are located in the visible range at 580 and $680 \mathrm{~nm}$, and their positions did not change as a function of temperature, which is typical of intracenter $d$ - $d$ transitions. The intensity of both bands decreased with increasing temperature; however, not in a parallel manner, indicating the presence of two different manganese species. The intensity of d-d transitions decreases with increasing temperature, but this effect alone may not explain why the band at $680 \mathrm{~nm}$ almost completely disappeared. The number of manganese species responsible for this band must have significantly decreased during heating in inert gas.

The most intense feature in the spectra was observed in the UV region, with a maximum in the $300-400 \mathrm{~nm}$ range. This band originates from ligand-to-metal, specifically, oxygen-to-manganese, charge transfer transitions. With time on stream and rising temperature, the intensity of the band in the 300-400 $\mathrm{nm}$ range decreases, and the maximum of the band shifts to higher energy (Fig. 1). Specifically, at a temperature of $323 \mathrm{~K}$ (at the beginning of the activation treatment) the maximum was located at $325 \mathrm{~nm}$, whereas at $773 \mathrm{~K}$ the maximum was at $300 \mathrm{~nm}$. The observed shift of the maximum was accompanied by a decrease of the overall width of the absorption feature. Charge transfer to manganese at a higher oxidation state (characterized by lower energy and higher intensity), is replaced by charge transfer to manganese at a lower oxidation state (characterized by higher energy and lower intensity). The overall spectral changes, including the disappearance of $d-d$ transitions thus indicate reduction of manganese, most likely to a valence of +II, because the $\mathrm{d}-\mathrm{d}$ transitions of $\mathrm{Mn}^{2+}$ are spin-forbidden. This interpretation is consistent with the previous XANES results, which show that the average valence of manganese decreases by about 0.2 to a value of $2.5 \pm 0.05$ during heating in inert gas [12]

The bands at 580 and $680 \mathrm{~nm}$ have been ascribed to d-d transitions of $\mathrm{Mn}^{2+}$ or $\mathrm{Mn}^{3+}$ [25]. The transition of $\mathrm{Mn}^{2+}$ in octahedral cubic surrounding that is lowest in energy, ${ }^{6} A_{1} \rightarrow{ }^{4} T_{1}$, falls into the range of $400-600 \mathrm{~nm}$ (Table 1), but it is spin forbidden and should not reach an intensity of the same order of magnitude as ligand-to-metal charge transfer bands. These considerations allow the conclusion that the bands at 580 and $680 \mathrm{~nm}$ do not belong to $\mathrm{Mn}^{2+}$ species.

The spectral changes observed during heating of MnSZ (2wt\% Mn) in a flow of $\mathrm{O}_{2}$ are shown in Fig. 2. The charge transfer transition at $320 \mathrm{~nm}$ and the band at $580 \mathrm{~nm}$ increased noticeably in intensity as the temperature was raised, the band at $680 \mathrm{~nm}$ increased marginally, if at all. The position of the maximum of the charge transfer band remained unchanged. When a sample of MnSZ (0.5 wt \% $\mathrm{Mn}$ ) was cooled to below room temperature in vacuum (Fig. 3), the band at $\approx 590 \mathrm{~nm}$ did not change position and decreased in intensity, as is characteristic of $d-d$ transitions. The band at $680 \mathrm{~nm}$ also did not shift as a function of temperature.

The bands at 580 and $680 \mathrm{~nm}$ cannot both be assigned to d-d transitions of $\mathrm{Mn}^{3+}$ ions [23] because the bands do not behave similarly as a function of temperature, 


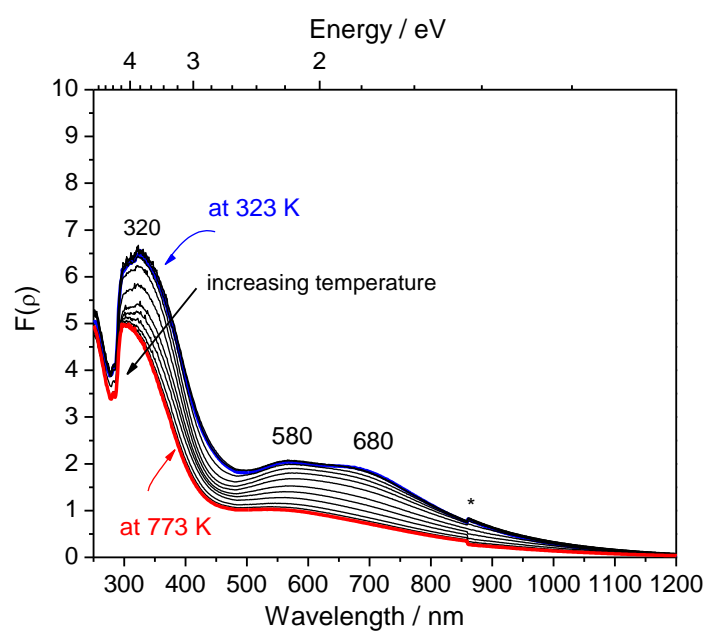

Fig. 1: Diffuse reflectance UV-vis spectra of manganesepromoted sulfated zirconia $(2.0 \mathrm{wt} \% \mathrm{Mn})$ in $20 \mathrm{~mL} / \mathrm{min}$ helium in the temperature range $323-773 \mathrm{~K}$. Asterisks denote artifacts.

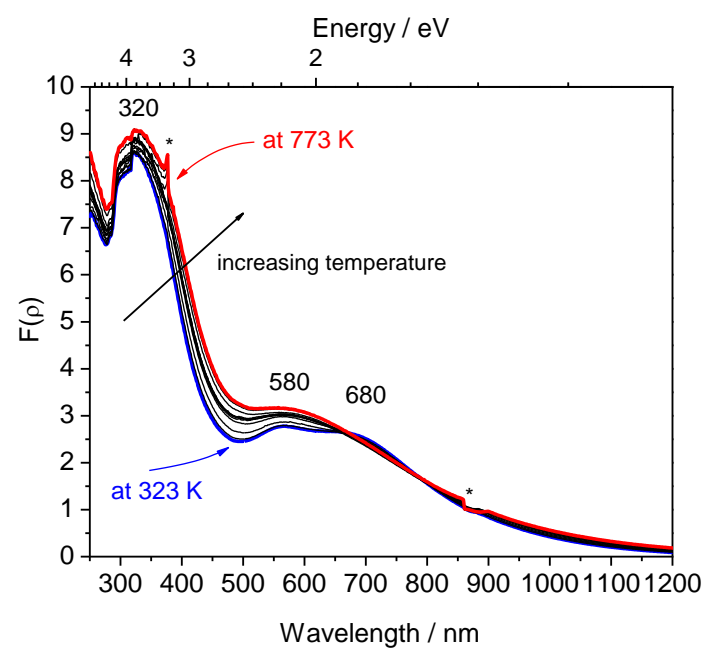

Fig. 2:Diffuse reflectance UV-vis spectra of manganese-promoted sulfated zirconia $(2.0 \mathrm{wt} \% \mathrm{Mn})$ in $40 \mathrm{~mL} / \mathrm{min}_{2}$ in the temperature range $323-773 \mathrm{~K}$. Asterisks denote artifacts.

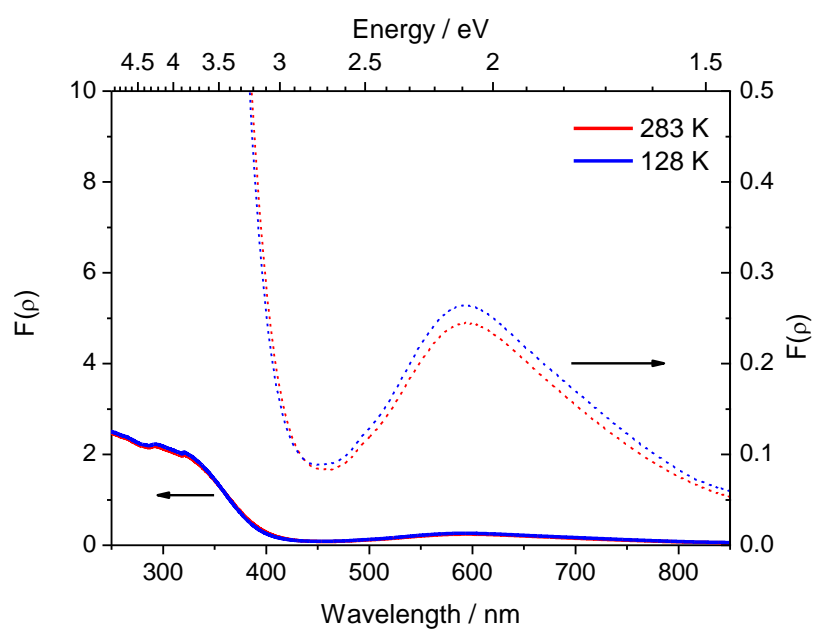

Fig. 3: Diffuse reflectance UV-vis spectra of MnSZ ( $0.5 \mathrm{wt} \% \mathrm{Mn})$ at low temperatures under roughing vacuum $(1 \mathrm{mbar})$. The same two spectra are shown twice, on two different scales (left and right y-axis). independent of the atmosphere (Figs. 1, 2, and 3). We exclude $d$ - $d$ transitions of $\mathrm{Zr}^{3+}$ because they fall into the range of 320-380 nm [42,43].

With $\mathrm{Mn}^{2+} \mathrm{d}-\mathrm{d}$ transitions excluded and oxidation of the initial $\mathrm{Mn}(\mathrm{II})$ beyond a valence of +IV during calcination unlikely, we consider d-d transitions of $\mathrm{Mn}^{3+}$ and $\mathrm{Mn}^{4+}$ species. The crystal field is stronger for the $\mathrm{Mn}^{4+}$ ion than that for the $\mathrm{Mn}^{3+}$ ion; for example in the cubic crystal field, the parameter $D q$ for $\mathrm{Mn}^{4+}$ ions [44] exceeds significantly that for $\mathrm{Mn}^{3+}$ ions. Thus, we ascribe the band at $680 \mathrm{~nm}$ to $\mathrm{Mn}^{3+}$ and the band at $580 \mathrm{~nm}$ to $\mathrm{Mn}^{4+}$ species.

\section{Model of manganese ions in the zirconia lattice}

\subsection{Hamiltonian of the system}

We employ the quasimolecular (cluster) model that considers a complex formed by the central ion, in this case manganese, and ligands, in this case the adjacent oxygen ions of the lattice. The displacements of the ligands are assumed to be a result of the modulation of the crystal field acting on the manganese ion by lattice vibrations.

The total Hamiltonian for a manganese ion is represented as

$$
H=H_{e}+H_{v}+H_{e v}
$$

where $H_{e}$ is the electronic Hamiltonian determining the wave functions and the eigenvalues of a manganese ion in a fixed nuclear configuration, this Hamiltonian includes the kinetic energy of the electrons in the $d$-shell as well as their interaction with the ligand surrounding. $H_{v}$ is the Hamiltonian of free lattice vibrations. We account only for the interaction of the manganese ions with the fully symmetric breathing mode of the nearest surrounding because this mode produces the maximum change of the potential energy per displacement unit. In this case the Hamiltonian $H_{v}$ takes on the form:

$$
H_{v}=\frac{\hbar \omega}{2}\left(q^{2}-\frac{\partial^{2}}{\partial q^{2}}\right)
$$

here $q$ is the symmetry-adapted vibrational coordinate corresponding to the full-symmetric (breathing) vibration, and $\omega$ is the frequency of this vibration. $H_{e v}$ is the vibronic interaction of the manganese ion with the fully symmetric vibration. In our model this interaction is supposed to be linear with respect to atomic displacements and can be represented in the following form: 


$$
H_{e v}=v(\mathbf{r}) q
$$

where $\mathbf{r}$ represents the set of electronic coordinates.

The function $v(\mathbf{r})$ (having the dimension of energy) is determined as the derivative of the electron-nuclear potential energy $W\left(\left|\mathbf{r}-\mathbf{R}_{\alpha}\right|\right)$ at the point $q=0$ :

$$
v(\mathbf{r})=\frac{1}{\sqrt{n}} \sum_{\alpha}\left(\frac{\partial W\left(\left|\mathbf{r}-\mathbf{R}_{\alpha}\right|\right)}{\partial \mathbf{R}_{\alpha}}\right)_{\mathbf{R}_{\alpha}=\mathbf{R}_{\alpha}^{0}}
$$

here $\mathbf{R}_{\alpha}$ are the coordinates of the ligand surrounding of a manganese ion and $\mathbf{R}_{\alpha}^{0}$ are their equilibrium values in the absence of electrons in the $d$-shell, $\alpha$ numbers the ligands in the first coordination sphere, and $n$ is the total number of these ligands. The energy $W\left(\left|\mathbf{r}-\mathbf{R}_{\alpha}\right|\right)$ appears as a term in the Hamiltonian $H_{e}$.

\subsection{Crystal field model}

Our next step is the choice of the model of the crystal field and the electron-vibrational interaction for all manganese species. We employ the exchange-charge model of the crystal field [45-50] that takes into account two contributions to the energy of the manganese ions in the crystal field, namely, the contribution arising from the interaction of the electrons in the d-shell of the manganese ions with the point charges $(p c)$ of the surrounding ligands and the contribution coming from the overlap of the $3 \mathrm{~d}$ orbital with the ligand orbitals. The latter is referred to as the contribution of exchange charges $(e c)$. In this model the parameters $B_{l}^{m}$ of the crystal field operator

$V_{c}=\sum_{\alpha} W\left(\left|\vec{r}-\vec{R}_{i \alpha}\right|\right)=\sum_{l, m} B_{l}^{m} Y_{l}^{m}(\vartheta, \varphi)$

are represented as

$B_{l}^{m}=B_{l}^{m(p c)}+B_{l}^{m(e c)}$

where the component

$B_{l}^{m(p c)}=\left(\frac{4 \pi}{2 l+1}\right) \sum_{\alpha} \frac{Z_{\alpha} e^{2}<r^{l}>}{\left(R_{\alpha}\right)^{l+1}} Y_{l}^{m^{*}}\left(\vartheta_{\alpha}, \varphi_{\alpha}\right)$

is determined in the usual manner [47-51] and depends on the positions of the ligands, their effective charges and radial integrals calculated with the radial wave- functions specified in Ref. 51 for the manganese ions. The component $B_{l}^{m(e c)}$

$$
B_{l}^{m(e c)}=\frac{8 \pi e^{2}}{5} G \sum_{\alpha} \frac{S_{l}\left(R_{\alpha}\right)}{R_{\alpha}} Y_{l}^{m^{*}}\left(\vartheta_{\alpha}, \varphi_{\alpha}\right)
$$

is proportional to a linear combination of squares of different type overlap integrals of the $3 \mathrm{~d}$ functions of the manganese ions and $2 \mathrm{~s}, 2 \mathrm{p}$ wave functions of the oxygen ligands [51]

$$
\begin{aligned}
& S_{p}\left(R_{\alpha}\right)=\left(S_{s}\left(R_{\alpha}\right)\right)^{2}+\left(S_{\sigma}\left(R_{\alpha}\right)\right)^{2}+\gamma_{p}\left(S_{\pi}\left(R_{\alpha}\right)\right)^{2} \\
& \gamma_{2}=1, \gamma_{4}=-4 / 3, S_{s}\left(R_{\alpha}\right)=<3 d, m=0 \mid 2 s>, \\
& S_{\sigma}\left(R_{\alpha}\right)=<3 d, m=0 \mid 2 p, m=0>, \\
& S_{\pi}\left(R_{\alpha}\right)=<3 d, m= \pm 1 \mid 2 p, m= \pm 1>\text { are overlap }
\end{aligned}
$$
integrals of the $3 d$ wave functions of manganese ions and $2 s, 2 p$ wave functions of the oxygen ligands, $G$ is the phenomenological parameter of the model, $Y_{p m}(\vartheta, \varphi)$ are normalized spherical harmonics. The operator $\nu(\mathbf{r})$ of interaction with the fully symmetric (breathing) mode can be obtained by substitution of the crystal field potential (5) into Eq. (4) and differentiation of the parameters $B_{l}^{m(p c)}$ and $B_{l}^{m(e c)}$ over the radii $\mathbf{R}_{\alpha}$.

\subsection{Form-function of the optical $d$-d transition in the semi-classical approximation}

In the subsequent sections the calculation of the crystal field splittings and vibronic coupling constants determining the profiles of the absorption bands of $\mathrm{Mn}^{3+}$ and $\mathrm{Mn}^{4+}$ will be performed in the exchange charge model of the crystal field with the aid of the relations listed above. We will employ the adiabatic approximation, neglecting the nuclear kinetic energy in the Hamiltonian $H_{v}$ (Eq. 2). The validity of this approximation for the optical band problem is restricted to the case of strong vibronic coupling or high temperatures [52]. Since the optical spectra under examination were measured in the temperature range 373-723 K this approximation proves to be applicable. In the adiabatic approximation the energies of the ground states $i$ and the excited states $f$ of the manganese ions represent the adiabatic potentials

$$
U_{i}(q)=\frac{\hbar \omega q^{2}}{2}+v_{i} Q
$$

$U_{f}(Q)=\Delta_{f}+v_{f} Q+\frac{\hbar \omega Q^{2}}{2}$ 
here $v_{i}=\langle i|v(\mathbf{r})| i\rangle$ and $v_{f}=\langle f|v(\mathbf{r})| f\rangle$ are the matrix elements of the operator of electron-vibrational interaction (Eq. 4) in the ground and excited states, respectively. In the adiabatic approximation the form function $F(\Omega)$ that allows for all intracenter optical transitions from the ground state $i$ to the excited states $f$ looks as follows:

$F(\Omega)=\left.\frac{1}{Z} \sum_{f} \overline{\left\langle i\left|\boldsymbol{u} \boldsymbol{d}_{\text {eff }}\right| \mathrm{f}\right\rangle}\right|^{2} \int_{-\infty}^{\infty} \operatorname{Exp}\left[-\frac{U_{i}(q)}{k_{B} T}\right] \delta\left(U_{f}(q)-U_{i}(q)-\hbar \Omega\right) d q$

where $\boldsymbol{d}_{\text {eff }}$ and $\boldsymbol{u}$ are the dipole moment and polarization vectors, respectively, $\Omega$ is the frequency of light, the symbol $\overline{|\ldots|^{2}}$ means averaging over light polarization, and

$Z=\left(\frac{2 k_{B} T \pi}{\hbar \omega}\right)^{1 / 2}\left(\exp \left(\frac{v_{i}^{2}}{2 k_{B} T \omega}\right)+\sum_{f} \exp \left(-\frac{\Delta_{f}}{k_{B} T}\right) \exp \left(\frac{v_{f}^{2}}{2 k_{B} T \hbar \omega}\right)\right)$

is the partition function, $\Delta_{f}$ is the crystal field gap between the excited $(f)$ and ground (i) state. Carrying out the integration in Eq. 10 for the form-function $F_{d d}(\Omega)$ that allows for intracenter optical transitions between the ground $i$ and the excited $f$ states of manganese ions we obtain

$$
\begin{aligned}
& F(\Omega)=Z^{-1} \overline{\sum_{f}\left|\left\langle i\left|\boldsymbol{u} \boldsymbol{d}_{e f f}\right| f\right\rangle\right|^{2}} \exp \left(\frac{v_{i}^{2}}{2 k_{B} T \hbar \omega}\right) v_{f}-\left.v_{i}\right|^{-1}\left(\frac{2 k_{B} T \pi}{\hbar \omega}\right)^{1 / 2} \\
& \exp \left(-\frac{\hbar \omega}{2 k_{B} T\left(v_{i}-v_{f}\right)^{2}}\left(\Delta_{f}-\hbar \Omega+\frac{v_{i}\left(v_{i}-v_{f}\right)}{\hbar \omega}\right)^{2}\right)
\end{aligned}
$$

The energy of the maximum of the $\mathrm{d}-\mathrm{d}$ band arising on the transition $i \rightarrow f$

$\hbar \Omega^{i f}=\Delta_{f}+\frac{v_{i}\left(v_{i}-v_{f}\right)}{\hbar \omega}$

should be attributed to the observed gap between the d-levels involved in the optical transition. The gap $\Delta_{f}$ is re-determined as a result of the d-electron shifting the ligands to new equilibrium positions.

In the subsequent sections we calculate the apparent absorption spectra with the aid of the relation $K(\Omega) \sim \Omega F(\Omega)$. We describe how we evaluate the energy spectrum, the vibronic coupling constants and the apparent absorption spectra of the $\mathrm{Mn}(\mathrm{III})$ and $\mathrm{Mn}(\mathrm{IV})$ ions in manganese-promoted sulfated zirconia.

\section{Crystal field splittings and vibronic inte- raction of $\mathrm{Mn}$ (III) ions}

One consequence of the incorporation of promoter ions into the zirconia lattice is the generation of oxygen vacancies for charge compensation (resulting from the lower valence of promoter ions in comparison to $\mathrm{Zr}^{4+}$ ). The vacancies provoke atomic displacements of the nearest or next nearest neighbors, and, in consequence, increase of the impurity concentration leads to a change of the spatial symmetry of the whole doped crystal. Much research has already been done to understand the changes in the structure of zirconia upon doping [53,54], but agreement regarding the magnitude and direction of the displacements of the oxygen and metal ions from their lattice positions is lacking. Such a situation arises because of the variety of compositions examined and different thermal histories of the samples. However, the main reason for the absence of detailed information on crystal rearrangement is the limited ability of experimental methods. Single-crystal studies using integrated intensities of Bragg reflections can only provide information about "the average structure" in which all unit cells are superimposed. Because of this superposition it is sometimes difficult to detect subtle atomic displacements occurring randomly throughout the crystal. Another experimental difficulty consists in resolving the displacements of zirconium and dopant cations. Therefore, in the present work, complementary methods are applied to provide insight into the structure of promoted zirconia oxide. This study is based on the combination of modeling the dopant-vacancy clusters and experimental optical absorption spectra.

A literature review shows that on the basis of the experimental data (X-ray absorption spectroscopy, X-ray and neutron diffraction, electron paramagnetic resonance) it is possible to predict the number of vacancies in the nearest surroundings of the impurity ion, the number of its nearest neighbor oxygen ions, the directions of the oxygen ions displacements and the symmetry of the nearest surrounding of the impurity ion $[42,42,55,56]$. Neutron-diffraction measurements [55] indicate that the presence of oxygen vacancies causes oxygen ion displacements along the $<100\rangle$ direction towards the vacancies (Fig. 4). On the basis of data from single-crystal X-ray diffraction using synchrotron radiation and EXAFS obtained for yttria-doped cubic stabilized zirconia it was proposed that in the nearest 8 -fold surrounding of the $\mathrm{Y}^{3+}$ ion two oxygen ions positioned along the body diagonal of the cube are missing (Fig. 5) so that the $\mathrm{Y}^{3+}$ ion has only six oxygen ligands [56]. EPR and optical spectra of $\mathrm{Zr}^{3+}$ in cubic stabilized zirconia were also successfully explained using a model that considers six-fold coordinated $\mathrm{Zr}^{3+}$ ions $[42,43]$. Electron energy loss spectroscopy fine structure analysis of the $\mathrm{Mn} \mathrm{L}_{23}$ edge provided evidence that in manganesestabilized cubic zirconia manganese is octahedrally coordinated [57] 


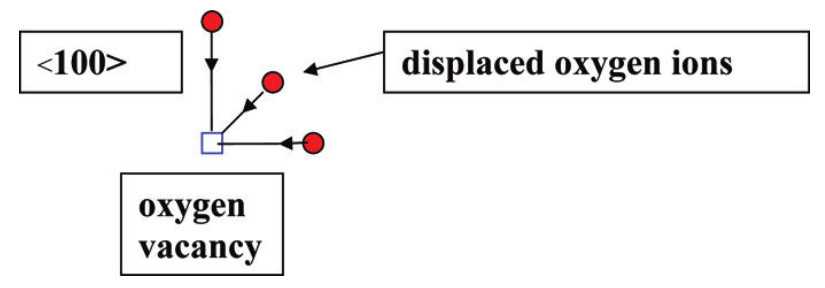

Fig. 4: Oxygen ion displacements towards the vacancy along the 100 direction

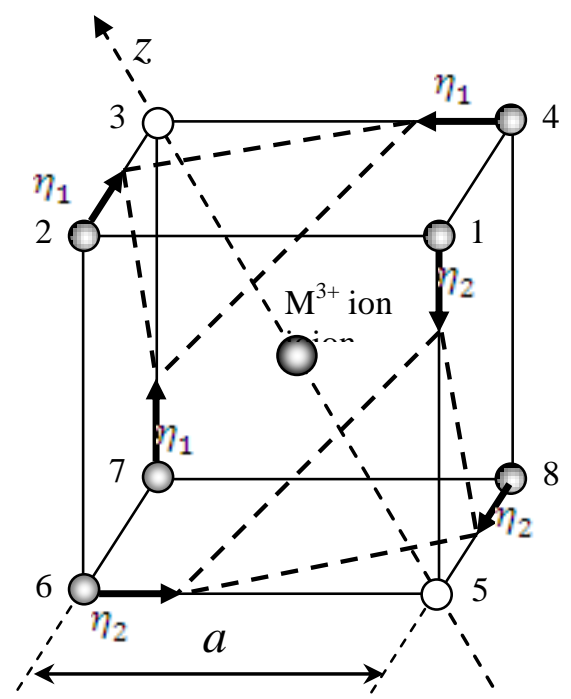

Fig. 5: Structural model of a $\mathrm{M}^{3+}$ metal center in zirconia showing the different displacements $\eta_{1}, \eta_{2}$ of the two terns of oxygen atoms towards the oxygen vacancies; $a$ is the cube edge

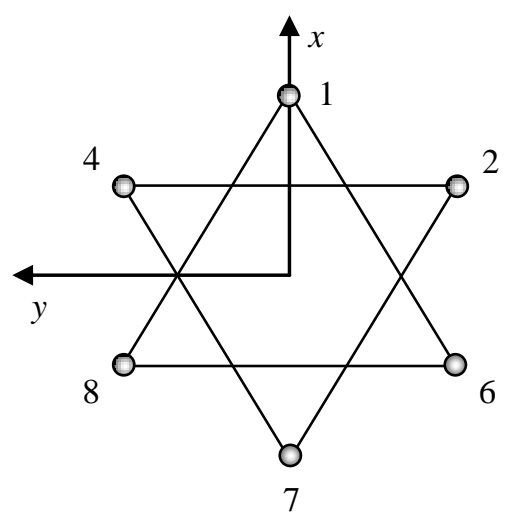

Fig. 6: Top view of the $\mathrm{Mn}^{3+}$ complex

We assume that introduction of $\mathrm{Mn}^{3+}$ ions instead of $\mathrm{Zr}^{4+}$ ions into the zirconia lattice induces oxygen vacancies for charge compensation, and the nearest surrounding of $\mathrm{Mn}^{3+}$ ions in $\mathrm{MnSZ}$ consists of 6 oxygen ions, which are shifted towards the two oxygen vacancies (Fig. 5). This assumption is in line with the results obtained in the examination of yttria-doped cubic stabilized zirconia $[42,43,56]$. To maintain an overall neutral state of the solid, oxygen vacancies and $\mathrm{Mn}^{3+}$ would have to exist in a ratio of 1:2; however, there is always a significant fraction of $\mathrm{Mn}^{2+}$ and vacancies in the model may be shared with adjacent metal ions with a valence lower than +IV. In Fig. 6, the top view of the $\mathrm{Mn}^{3+}$ complex is given. Following $[42,43,55]$, we model the local rearrangements of the oxygen anions as <100> displacements $\eta_{1}$ and $\eta_{2}$ of the two terns of oxygens towards each of the two vacancies within a cube (Fig. 5). In this approximation, the spherical angles $\vartheta_{i}$ of the six oxygens and the distances between the central $\mathrm{Mn}^{3+}$ ion and the two terns of oxygen ions are expressed as

$$
\begin{aligned}
& R_{i}=\frac{1}{2} \sqrt{4 \eta_{i}^{2}-4 a \eta_{i}+3 a^{2}} \\
& \theta i_{i}=\operatorname{ArcCos}\left[(-1)^{i+1} \frac{a+2 \eta_{i}}{2 \sqrt{3} R_{i}}\right](i=1,2),
\end{aligned}
$$

where $a$ is the cube edge and $\eta_{1}$ and $\eta_{2}$ are the displacements of the oxygen ions shown in Fig. 5.

The spherical coordinates of the ligand surrounding of the $\mathrm{Mn}^{3+}$ ions are listed in Table 2.

Table2: Spherical coordinates of the ligand surrounding of the $\mathrm{Mn}^{3+}$ ions

$\begin{array}{cccc} & R(\AA) & \varphi_{i}(\mathrm{deg}) & \theta_{i}(\mathrm{deg}) \\ 1 & R_{2} & 0 & \theta_{2} \\ 2 & R_{1} & 300 & \theta_{1} \\ 4 & R_{1} & 60 & \theta_{1} \\ 6 & R_{2} & 240 & \theta_{2} \\ 7 & R_{1} & 180 & \theta_{1} \\ 8 & R_{2} & 120 & \theta_{2}\end{array}$

Table 3: Crystal field parameters $B_{l}^{m}$ (in $\mathrm{cm}^{-1}$ ) for $\mathrm{Mn}^{3+}$ calculated with $\eta_{1}=0.17 \AA, \eta_{2}=0.23 \AA, G=3.65$

\begin{tabular}{crcc} 
& pc & ec & total \\
$B_{2}^{0}$ & -21090 & -8255 & -29345 \\
$B_{4}^{0}$ & -1282 & -3873 & -5155 \\
$B_{4}^{3}$ & 4760 & 14330 & 19090 \\
\hline
\end{tabular}

The dopant ions represent centers of small radii, and it is sufficient to account for interaction of these ions with ions of their first coordination sphere [45-50]. Further on we calculate in this approximation the operators of the crystal field and electron-vibrational interaction assuming that the point charge of the oxygen ligands is equal to $2 \mathrm{e}$.

For $\mathrm{Mn}^{3+}$ species, the crystal field operator of $\mathrm{C}_{3 \mathrm{v}}$ symmetry written in the frame of reference related to the $\mathrm{C}_{3}$ axis (z-axis) shown in Fig. 5 is 

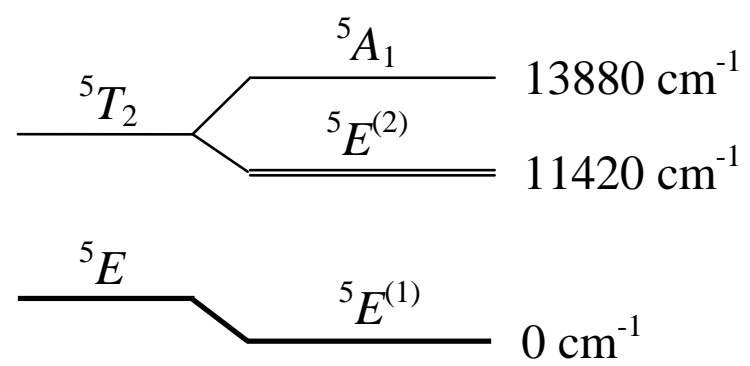

Fig. 7: Crystal field splittings of the $\mathrm{Mn}^{3+}$ ion calculated with the parameters $\eta_{1}=0.17 \AA, \eta_{2}=0.23 \AA, G=3.65$

$$
\begin{aligned}
& V_{c r}=B_{2}^{0} Y_{2,0}(\theta, \varphi)+B_{4}^{0} Y_{4,0}(\theta, \varphi)+ \\
& B_{4}^{3}\left(Y_{4,3}(\theta, \varphi)-Y_{4,-3}(\theta, \varphi)\right)
\end{aligned}
$$

where $B_{l}^{m}$ are the parameters of the crystal field. The numerical values of these parameters estimated in the exchange-charge model of the crystal field with the aid of Eq. 6-8 are quoted in Table 3, which also identifies the partial contributions of the exchange and point charges.

In calculations of the crystal field the values $G=3.65, \eta_{1}=0.17 \AA, \eta_{2}=0.23 \AA$ were taken for the phenomenological parameters of the model, $G$ (Eq. 8) and $\eta_{i}(i-1,2)$ (Eq. 14). These values were obtained from comparison of the calculated and observed band maxima. As an illustration, the analytical expressions for the parameters $B_{l}^{m}$ for the $\mathrm{Mn}^{3+}$ complex are given in Appendix 1 (Eqs. A.1-A.3).

In the trigonal crystal field the ground state of the $\mathrm{Mn}^{3+}$ ion is a doublet ${ }^{5} E^{(1)}$ (Fig. 7), while the excited cubic term of this ion ${ }^{5} T_{2}$ is split into two levels ${ }^{5} A_{1}$ and ${ }^{5} E^{(2)}$. The wave functions of these levels have the form:

$$
\begin{aligned}
& \left|{ }^{5} A_{1}\right\rangle=\left|x_{1} x_{-1} u_{-1} u_{1}\right|, \\
& \left|{ }^{5} E^{(1)} u_{-}\right\rangle=C_{11}^{(1)}\left|x_{1} x_{0} x_{-1} u_{-1}\right|+C_{12}^{(1)}\left|x_{-1} x_{0} u_{-1} u_{1}\right|, \\
& \left|{ }^{5} E^{(1)} u_{+}\right\rangle=C_{12}^{(1)}\left|x_{1} x_{0} x_{-1} u_{1}\right|-C_{11}^{(1)}\left|x_{1} x_{0} u_{-1} u_{1}\right| \\
& \left|{ }^{5} E^{(2)} u_{-}\right\rangle=C_{11}^{(2)}\left|x_{1} x_{0} x_{-1} u_{-1}\right|+C_{12}^{(2)}\left|x_{-1} x_{0} u_{-1} u_{1}\right|, \\
& \left|{ }^{5} E^{(2)} u_{+}\right\rangle=C_{12}^{(2)}\left|x_{1} x_{0} x_{-1} u_{1}\right|-C_{11}^{(2)}\left|x_{1} x_{0} u_{-1} u_{1}\right|
\end{aligned}
$$

The numerical values of the coefficients $C_{11}^{(1)}=0.9881, \quad C_{12}^{(1)}=0.1536, \quad C_{11}^{(2)}=-0.1536$, $C_{12}^{(2)}=0.9881$ of the wave functions (Eq. 16) were obtained by diagonalization of the crystal field potential (Eq.
15). The trigonal one-electron states (complex trigonal basis) relevant to the trigonal coordinate system (Figs.5,6) are expressed in terms of the d-functions $\xi=y z, \eta=x z, \zeta=x y\left(t_{2 g}\right), \quad u=3 z^{2}-r^{2}, v=\sqrt{3}\left(x^{2}-y^{2}\right)\left(e_{g}\right)$ defined in the tetragonal basis as follows:

$$
\begin{aligned}
& \left\{\begin{array}{l}
\left|x_{+}\right\rangle=-(1 / \sqrt{3})\left(\varepsilon \xi+\varepsilon^{*} \eta+\zeta\right), \\
\left|x_{-}\right\rangle=(1 / \sqrt{3})\left(\varepsilon^{*} \xi+\varepsilon \eta+\zeta\right), \\
\left|x_{0}\right\rangle=(1 / \sqrt{3})(\xi+\eta+\zeta),
\end{array}\right. \\
& \left\{\begin{array}{l}
u_{+}=-(1 / \sqrt{2})(u+i v), \quad \varepsilon=\exp (2 \pi i / 3) . \\
u_{-}=(1 / \sqrt{2})(u-i v),
\end{array}\right.
\end{aligned}
$$

The

$$
\text { energy }
$$

$\Delta_{A}=E\left({ }^{5} A_{1}\right)-E\left({ }^{5} E^{(1)}\right)=13880 \mathrm{~cm}^{-1}$

$$
\Delta_{E}=E\left({ }^{5} E^{(2)}\right)-E\left({ }^{5} E^{(1)}\right)=11420 \mathrm{~cm}^{-1} \text { were calcu- }
$$

lated using the crystal field potential (Eq. 15), the wave functions (Eq. 16) and the crystal field parameters given in Table 3. Thus, the absorption band originating from the $\mathrm{Mn}^{3+}$ species can be assigned to the optical transitions ${ }^{5} E^{(1)} \rightarrow{ }^{5} E^{(2)},{ }^{5} E^{(1)} \rightarrow{ }^{5} A_{1}$. To obtain the scheme of the adiabatic potential sheets and to calculate the shape of the absorption band arising from the $\mathrm{Mn}^{3+}$ species with the aid of Eqs. 5-8 we estimated the corresponding vibronic coupling constants $v\left({ }^{5} A_{1}\right), v\left({ }^{5} E^{(2)}\right), v\left({ }^{5} E^{(1)}\right)$. In Table 4 , the vibronic constants for various states of the $\mathrm{Mn}^{3+}$ ion are given and broken down into the contributions from the electrostatic field of point ligand charges and the exchange charge field. It is seen that the main contribution to the vibronic coupling constants comes from the exchange charge field.

The positions of the $d-d$ bands that form the total absorption spectrum of the $\mathrm{Mn}^{3+}$ ions can be illustrated by the scheme of the adiabatic potentials as shown in Fig. 8, where $q$ is the full-symmetric coordinate (the breathing mode) of the local surrounding of the $\mathrm{Mn}^{3+}$ ions in sulfated zirconia. The pattern of the adiabatic potentials

$$
\begin{aligned}
& U_{E^{(1)}}(q)=v\left({ }^{5} E^{(1)}\right) q+\frac{\hbar \omega}{2} q^{2}, \\
& U_{E^{(2)}}(q)=\Delta_{E}+v\left({ }^{5} E^{(2)}\right) q+\frac{\hbar \omega}{2} q^{2} \\
& U_{A}(q)=\Delta_{A}+v\left({ }^{5} A_{1}\right) q+\frac{\hbar \omega}{2} q^{2}
\end{aligned}
$$

depends on the energy gaps $\Delta_{A}$ and $\Delta_{E}$ between the electronic states in the crystal field and the vibronic coupling constants. In Fig. 8, the maxima of the absorption bands arising from the transitions from the ground adiabatic potential sheet to the excited ones are indicated. It is seen that $\mathrm{Mn}^{3+}$ species contribute to the visible and NIR part of the spectra. 


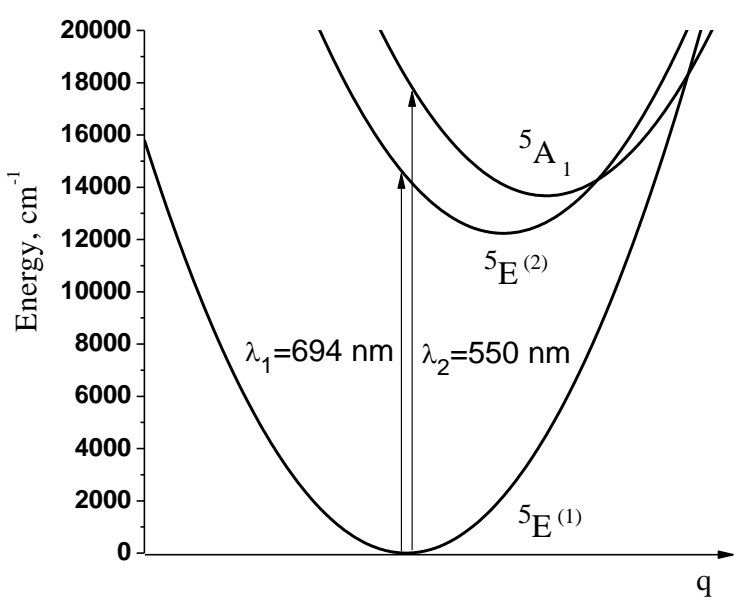

Fig. 8: Adiabatic potentials for the $\mathrm{Mn}^{3+}$ ions calculated with the parameters: $\quad \eta_{1}=0.17 \AA \AA \quad \eta_{2}=0.23 \quad \AA, \quad G=3.65$, $\hbar \omega=615 \mathrm{~cm}^{-1}[58]$. The wavelengths $\lambda_{i}$ indicate the maxima of the absorption bands arising on the transitions from the ground adiabatic potential sheet to the excited ones

\section{Oscillator strengths for the transitions of Mn3+ ions}

To calculate the shape of the absorption band arising from the $\mathrm{Mn}^{3+}$ ions we consider the intensities of the optical transitions of these ions. The states of the $\mathrm{Mn}^{3+}$ ion belong to even parity. The parity-forbidden electric-dipole transitions between these states become allowed because of the presence of the static odd-parity potential $V_{\text {odd }}$ for the $\mathrm{Mn}^{3+}$ complexes in sulfated zirconia that have no inversion center. The effective dipole moment $\boldsymbol{d}_{\text {eff }}$ can be presented as [44]

$\boldsymbol{d}_{\text {eff }} \sim \frac{2 V_{\text {odd }} \boldsymbol{d}}{\Delta}$,

where $\Delta$ is the effective energy gap between the $3 d$ and odd-parity levels in the energy spectrum, $\boldsymbol{d}$ is the electric dipole moment expressed as

$$
\begin{aligned}
& \boldsymbol{d}=-d_{-} \hat{\boldsymbol{k}}^{+}-d_{+} \hat{\boldsymbol{k}}^{-}+d_{0} \hat{\boldsymbol{k}}_{0}, \\
& d_{+}=-\frac{e r \sqrt{4 \pi}}{\sqrt{3}} Y_{1,1}(\theta, \varphi), \\
& d_{-}=-\frac{e r \sqrt{4 \pi}}{\sqrt{3}} Y_{1,-1}(\theta, \varphi), \\
& d_{0}=-\frac{e r \sqrt{4 \pi}}{\sqrt{3}} Y_{1,0}(\theta, \varphi)(20)
\end{aligned}
$$

and $\hat{\boldsymbol{k}}^{+}=-\frac{1}{\sqrt{2}}(\boldsymbol{i}+i \boldsymbol{j}), \hat{\boldsymbol{k}}^{-}=\frac{1}{\sqrt{2}}(\boldsymbol{i}-i \boldsymbol{j}), \hat{\boldsymbol{k}}^{0}=\hat{\boldsymbol{k}}$.

Finally, $\boldsymbol{i}, \boldsymbol{j}$ and $\boldsymbol{k}$ are the unit vectors in the directions $x, y$ and $z$ of the trigonal coordinate axes (Figs. 5,6), respectively. To estimate the oscillator strengths of the transitions ${ }^{5} E^{(1)} \rightarrow{ }^{5} E^{(2)}$ and ${ }^{5} E^{(1)} \rightarrow{ }^{5} A_{1}$ with the aid of Eq. 19 we use the odd-parity crystal field potential $V_{\text {odd }}$ that corresponds to the trigonal symmetry of the $\mathrm{MnO}_{6}$ complex. The general form of this operator in a first approximation looks as follows

$$
V_{\text {odd }}=a(r) Y_{1,0}(\theta, \varphi) \text {, }
$$

where $a(r)$ represents the radial part of the potential $V_{\text {odd }}$. In fact, in the point charge model of the crystal field, this term represents the main contribution to the oscillator strengths. Using Eqs. 19-21, the matrix elements of the effective dipole moment for all optical transitions in $\mathrm{Mn}^{3+}$ ions were calculated. Omitting the details of the calculations we quote only the normalized values

$$
\begin{aligned}
& f_{\Sigma_{E^{(1)} \rightarrow \Gamma}}=\sum_{\gamma, \gamma^{\prime}} \overline{\left.\left\langle\Gamma \gamma^{\prime}\left|d_{e f f}\right| E^{(1)} \gamma\right\rangle\right|^{2}}, \\
& \left\{\sum_{\gamma, \gamma^{\prime}} \overline{\left.\left|{ }^{5} E_{\gamma^{\prime}}^{(2)}\right| d_{e f f}{ }^{5} E_{\gamma}^{(1)}\right\rangle\left.\right|^{2}}+\sum_{\gamma} \overline{\left.\left|{ }^{5} A_{1}\right| d_{e f f}\left|{ }^{5} E_{\gamma}^{(1)}\right\rangle\right|^{2}}\right\}
\end{aligned}
$$

of the matrix elements of the dipole moment for different optical transitions in $\mathrm{Mn}^{3+}$ species:

$$
f_{5_{E^{(1)} \rightarrow E^{(2)}}}=0.97, f_{5_{E^{(1)} \rightarrow A_{1}}}=0.03 \text {. It is worth }
$$
noting that the oscillator strength of the ${ }^{5} E^{(1)} \rightarrow^{5} A_{1}$ transition is small compared with that of the ${ }^{5} E^{(1)} \rightarrow{ }^{5} E^{(2)}$ transition. The simulation of the absorption coefficient was performed using the relation $\mathrm{K}_{\mathrm{Mn}^{3+}}(\Omega) \sim x_{\mathrm{Mn}^{3+}} \Omega_{\mathrm{Mn}^{3+}}(\Omega)$ (where $x_{\mathrm{Mn}^{3+}}$ is the relative concentration of $\mathrm{Mn}^{3+}$ ions) and Eqs. 11 and 12. In the calculations, the parameters given in Table 4 , the values $f_{5^{(1)} \rightarrow \Gamma}$ and the energy splittings shown in Fig. 7 were employed. The total calculated and experimental spectra arising from $\mathrm{Mn}^{3+}$ and $\mathrm{Mn}^{4+}$ species will be discussed in Section 8 . 
Table 4: Vibronic coupling constants $\left(\right.$ in $\mathrm{cm}^{-1}$ ) for $\mathrm{Mn}^{3+}$ in the case of $\eta_{1}=0.17 \AA, \eta_{2}=0.23 \AA, G=3.65$

\begin{tabular}{lrrr} 
& $\mathrm{pc}$ & \multicolumn{1}{c}{ ec } & \multicolumn{1}{c}{ total } \\
$v\left({ }^{5} \mathrm{~A}_{1}\right)$ & 420 & -1650 & -1230 \\
$v\left({ }^{5} \mathrm{E}^{(2)}\right)$ & 535 & -1045 & -510 \\
$v\left({ }^{5} \mathrm{E}^{(1)}\right)$ & -740 & 1870 & 1130 \\
\hline
\end{tabular}

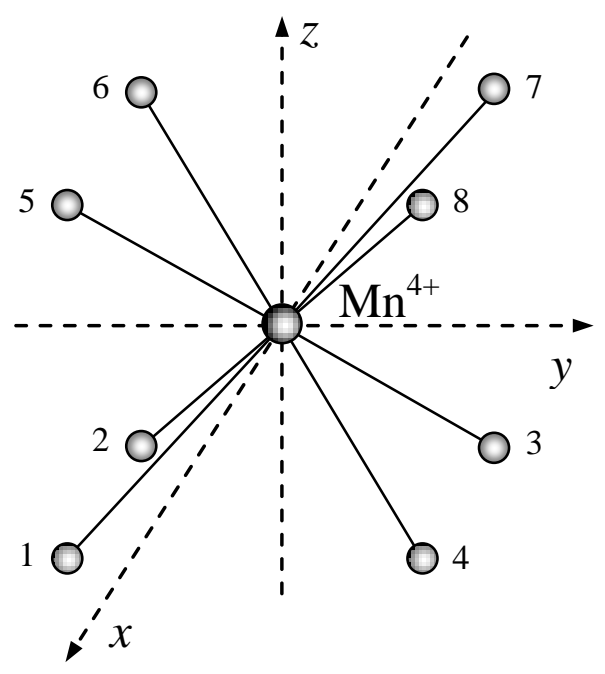

Fig. 9: Geometrical structure of the $\mathrm{Mn}^{4+}$ center: $-\mathrm{Mn}^{4+}, \mathrm{O}$ oxygen

\section{Crystal field splittings, vibronic interaction and intensities of optical transitions of $\mathrm{Mn}(\mathrm{IV})$ ions}

When $\mathrm{Mn}^{4+}$ substitutes $\mathrm{Zr}^{4+}$, the number of oxygen ligands surrounding the metal cation is assumed to remain unchanged at eight (Fig. 9). Modeling of the $\mathrm{O}^{2-}$ ions surrounding the $\mathrm{Mn}^{4+}$ ions is performed in the following way: (i) The distances between 8 oxygen ions and the $\mathrm{Zr}^{4+}$ ion in tetragonal stabilized zirconia were calculated from the structural data in [58]. These radii take on the following values: O1: $R_{1}=2.366 \AA$ O2: $R_{2}=2.083 \AA$, O3: $R_{3}=2.366 \AA$, O4: $R_{4}=2.083 \AA$, O5: $R_{5}=2.083 \AA$, O6: $R_{6}=2.366 \AA$, O7: $R_{7}=2.083 \AA$, O8: $R_{8}=2.366 \AA$. (ii) The radius of the $\mathrm{Zr}^{4+}$ ion is equal to $\mathrm{R}_{\mathrm{Zr} 4+}=0.82 \AA$, and the radius of the $\mathrm{O}^{2-}$ ion is $1.36 \AA$. Thus, the mean distance between these ions is $2.18 \AA$. The radius of the $\mathrm{Mn}^{4+}$ ion is $\mathrm{R}_{\mathrm{Mn} 4+}=0.52 \AA$, resulting in a mean distance $\mathrm{Mn}^{4+}-\mathrm{O}^{2-}$ of $1.88 \AA$ A. (iii) Assuming that the substitution of $\mathrm{Zr}^{4+}$ by $\mathrm{Mn}^{4+}$ only changes the distances between the metal ion and the oxygen ligands, the following approximate relations, where the radii are given in $\AA$,
Table 5: Distances between the $\mathrm{Mn}^{4+}$ Ion and the NearestNeighbor Oxygen Ions and Spherical Angles of the Oxygen Ions ${ }^{58}$

$\begin{array}{cccc} & R_{i}(\mathrm{~A}) & \varphi_{i}(\mathrm{deg}) & \theta_{i}(\mathrm{deg}) \\ 1 & 2.04 & 315 & 120 \\ 2 & 2.04 & 225 & 120 \\ 3 & 2.04 & 135 & 141 \\ 4 & 2.04 & 45 & 120 \\ 5 & 1.80 & 315 & 50 \\ 6 & 1.80 & 225 & 50 \\ 7 & 1.80 & 135 & 71 \\ 8 & 1.80 & 45 & 50\end{array}$

$1.88 / 2.18=\mathrm{x} / 2.366$,

$1.88 / 2.18=\mathrm{y} / 2.083$,

were used to determine the $\mathrm{Mn}-\mathrm{O}$ distances in the complex $\mathrm{Mn}(\mathrm{IV}) \mathrm{O}_{8}$. The resulting numerical values for the eight Mn-O bonds $R_{i}$ are given in Table 5. The values of the spherical angles $\theta_{i}$ and $\varphi_{i}$ for the oxygen ligands (Table 5) were taken to be the same as for the complex $\mathrm{Zr}(\mathrm{IV}) \mathrm{O}_{8}$ [58].

The crystal field potential for the $\mathrm{Mn}^{4+}$ ions is

$$
\begin{aligned}
& V_{c r}(\theta, \varphi)=B_{2}^{0} Y_{2,0}(\theta, \varphi)+B_{4}^{0} Y_{4,0}(\theta, \varphi)+B_{2}^{1}\left(Y_{2,-1}(\theta, \varphi)-Y_{2,1}(\theta, \varphi)\right)+ \\
& i C_{2}^{1}\left(Y_{2,-1}(\theta, \varphi)+Y_{2,1}(\theta, \varphi)\right)+i C_{2}^{2}\left(Y_{2,-2}(\theta, \varphi)-Y_{2,2}(\theta, \varphi)\right)+ \\
& B_{4}^{1}\left(Y_{4,-1}(\theta, \varphi)-Y_{4,1}(\theta, \varphi)\right)+i C_{4}^{1}\left(Y_{4,-1}(\theta, \varphi)+Y_{4,1}(\theta, \varphi)\right)+ \\
& i C_{4}^{2}\left(Y_{4,-2}(\theta, \varphi)-Y_{4,2}(\theta, \varphi)\right)+B_{4}^{3}\left(Y_{4,-3}(\theta, \varphi)-Y_{4,3}(\theta, \varphi)\right)+ \\
& i C_{4}^{3}\left(Y_{4,-3}(\theta, \varphi)+Y_{4,3}(\theta, \varphi)\right)+B_{4}^{4}\left(Y_{4,-4}(\theta, \varphi)+Y_{4,4}(\theta, \varphi)\right)
\end{aligned}
$$

As in Section 5, the parameters of the crystal field potential for the $\mathrm{Mn}^{4+}$ ion were estimated in the exchange-charge model of the crystal field using Eqs. 6-8. The phenomenological parameter $G=6.3$ that enters in the exchange charge part of the crystal field (Eq. 8) was determined from comparison of the calculated and observed maximum of the band arising from $\mathrm{Mn}^{4+}$ species. The numerical values of the parameters $B_{l}^{m}$ and $C_{l}^{m}$ and the contributions of the exchange and point charges to these parameters are given in Table 6.

The crystal field potential (Eq. 24) mixes the ground ${ }^{4} T_{1}\left(t_{2}^{2} e\right)$, first excited ${ }^{4} T_{2}\left(t_{2}^{2} e\right)$ and the second excited ${ }^{4} A_{2}\left(t_{2}^{3}\right)$ cubic terms of the $\mathrm{Mn}^{4+}$ ion and splits them into seven nondegenerate levels with wavefunctions 
Table 6: Crystal Field Parameters (in $\mathrm{cm}^{-1}$ ) for the $\mathrm{Mn}^{4+}$ Species

\begin{tabular}{lcccccc} 
& $B_{2}^{0}$ & $B_{4}^{0}$ & $B_{2}^{1}$ & $B_{4}^{1}$ & $B_{4}^{3}$ & \multicolumn{1}{c}{$B_{4}^{4}$} \\
pc & -2265 & -4750 & 3760 & 1345 & 160 & -4300 \\
ec & -3670 & -16580 & 2185 & 4620 & 400 & -15980 \\
total & -5935 & -21330 & 5945 & 5965 & 560 & -20280 \\
& $C_{2}^{1}$ & $C_{2}^{2}$ & \multicolumn{2}{c}{$C_{4}^{1}$} & $C_{4}^{2}$ & $C_{4}^{3}$ \\
& -3760 & 450 & -1345 & 480 & 160 \\
pc & -2185 & 220 & -4620 & 1675 & 400 \\
ec & -5945 & 670 & -5965 & 2155 & 560 \\
total & & & & &
\end{tabular}

Table 7: Numerical Values of the Expansion Coefficients $C_{k}^{(i)}$ of the Wave Functions of the $\mathrm{Mn}^{4+}$ Ion

\begin{tabular}{llrrlccl}
$\varphi_{i}$ & $C_{1}^{(i)}$ & \multicolumn{1}{c}{$C_{2}^{(i)}$} & \multicolumn{1}{c}{$C_{3}^{(i)}$} & \multicolumn{1}{c}{$C_{4}^{(i)}$} & \multicolumn{1}{c}{$C_{5}^{(i)}$} & \multicolumn{1}{c}{$C_{6}^{(i)}$} & \multicolumn{1}{c}{$C_{7}^{(i)}$} \\
$\varphi_{1}$ & -0.0062 & 0.0286 & 0.0286 & 0 & -0.0862 & 0.0862 & 0.9917 \\
$\varphi_{2}$ & -0.1244 & -0.0271 & -0.0271 & 0 & -0.6959 & 0.6959 & -0.1202 \\
$\varphi_{3}$ & 0 & 0.0220 & -0.0220 & 0.0921 & -0.7038 & -0.7038 & 0 \\
$\varphi_{4}$ & 0 & 0.0842 & -0.0842 & -0.9890 & -0.0621 & -0.0621 & 0 \\
$\varphi_{5}$ & 0.2605 & -0.6821 & -0.6821 & 0 & -0.0002 & 0.0002 & 0.0409 \\
$\varphi_{6}$ & 0 & -0.7017 & 0.7017 & -0.1158 & -0.0295 & -0.0295 & 0 \\
$\varphi_{7}$ & -0.9574 & -0.1823 & -0.1823 & 0 & 0.0909 & -0.0909 & 0.0203
\end{tabular}

\begin{tabular}{|c|c|}
\hline 7 & $27297 \mathrm{~cm}^{-1}$ \\
\hline 6 & \multirow{2}{*}{$\begin{array}{l}16693 \mathrm{~cm}^{-1} \\
16660 \mathrm{~cm}^{-1}\end{array}$} \\
\hline 5 & \\
\hline 4 & $12540 \mathrm{~cm}^{-1}$ \\
\hline 3 & \multirow{2}{*}{$\begin{array}{l}4193 \mathrm{~cm}^{-1} \\
3232 \mathrm{~cm}^{-1}\end{array}$} \\
\hline 2 & \\
\hline 1 & \\
\hline
\end{tabular}

Fig. 10: Crystal field levels of the $\mathrm{Mn}^{4+}$ ion in sulfated zirconia

$\varphi_{i}=\sum_{k=1}^{7} C_{k}^{(i)} \Psi_{k}$

where

$$
\begin{aligned}
& \Psi_{1}=\left|t_{2}^{3},{ }^{4} A_{2}, S=3 / 2, M_{S}=3 / 2\right\rangle=-|\xi \eta \zeta|, \\
& \Psi_{2}=\left|t_{2}^{2} e,{ }^{4} T_{2 \xi}, S=3 / 2, M_{S}=3 / 2\right\rangle=(\sqrt{3}|\eta \zeta u|+|\eta \zeta v|) / 2
\end{aligned}
$$

$$
\begin{aligned}
& \Psi_{3}=\left|t_{2}^{2} e,{ }^{4} T_{2 \eta}, S=3 / 2, M_{S}=3 / 2\right\rangle=(-\sqrt{3}|\zeta \xi u|+|\eta \xi v|) / 2 \\
& , \Psi_{4}=\left|t_{2}^{2} e,{ }^{4} T_{2 \zeta}, S=3 / 2, M_{S}=3 / 2\right\rangle=-|\xi \eta v| \\
& \Psi_{5}=\left|t_{2}^{2} e,{ }^{4} T_{1 \alpha}, S=3 / 2, M_{S}=3 / 2\right\rangle=(\sqrt{3}|\eta \zeta v|-|\eta \zeta u|) / 2 \\
& \Psi_{6}=\left|t_{2}^{2} e,{ }^{4} T_{1 \beta}, S=3 / 2, M_{S}=3 / 2\right\rangle=-(\sqrt{3}|\zeta \xi v|+|\zeta \xi u|) / 2 \\
& , \\
& \Psi_{7}=\left|t_{2}^{2} e,{ }^{4} T_{1 \gamma}, S=3 / 2, M_{S}=3 / 2\right\rangle=|\xi \eta u|
\end{aligned}
$$

$S$ is the total spin, $M_{S}$ is the spin projection and the conventional notation $|. .$.$| is used for the Slater determi-$ nants. The coefficients $C_{k}^{(i)}$ of the wave functions (Eq. 25) are given in Table 7, and the crystal field levels of the $\mathrm{Mn}^{4+}$ ions and their energies are illustrated in Fig. 10. The numbering of levels in Fig. 10 corresponds to that of the wavefunctions in Table 7. While diagonalizing the crystal field matrix in the basis of states (Eq. 26) the energy difference $\sim 12 B$ (with $\mathrm{B}$ the Racah parameter) between the cubic states ${ }^{4} A_{2}\left(t_{2}^{3}\right)$ and ${ }^{4} T_{1}\left(t_{2}^{2} e\right),{ }^{4} T_{2}\left(t_{2}^{2} e\right)$ provided by Coulomb interaction [44] was also taken into account. The shapes of the adiabatic potential sheets for $\mathrm{Mn}^{4+}$ ions (Fig. 11) can be easily calculated with the aid of an equation similar to Eq. 18 and the numerical values of the vibronic coupling constants, given in Table 8 for the states of the $\mathrm{Mn}^{4+}$ ions participating in optical transitions. As for the $\mathrm{Mn}^{3+}$ ion, the vibronic coupling constants for the $\mathrm{Mn}^{4+}$ ion were calculated using Eqs. 4-8. For each $\mathrm{Mn}^{4+}$ level participating in optical transitions, the vibronic coupling constant is represented as a sum of contributions arising from the point charge and exchange charge crystal field (Table 8).

Table 8: Vibronic Coupling Constants $v_{i}=\left\langle i\left|\hat{V}_{A_{1}}\right| i\right\rangle\left(\mathrm{in} \mathrm{cm}^{-1}\right)$ for $\mathrm{Mn}^{4+}$ Species

\begin{tabular}{rrrr} 
& \multicolumn{1}{c}{ pc } & \multicolumn{1}{c}{ ec } & \multicolumn{1}{c}{ total } \\
$v_{1}$ & 90 & 215 & 305 \\
$v_{2}$ & -420 & -1055 & -1475 \\
$v_{3}$ & -500 & -1225 & -1725 \\
$v_{4}$ & -555 & 790 & 235 \\
$v_{5}$ & -390 & -1470 & -1860 \\
$v_{6}$ & -1430 & 115 & -1315 \\
$v_{7}$ & 175 & -5320 & -5145
\end{tabular}


Table 9: Normalized Oscillator Strengths f1fi for the transitions $|1\rangle \rightarrow|i\rangle(\mathrm{i}=2-7)$ in $\mathrm{Mn}^{4+}$ Species

$\begin{array}{lccc}\text { transition } & f & \text { transition } & f \\ 1 \rightarrow 2 & 0.11 & 1 \rightarrow 5 & 0.32 \\ 1 \rightarrow 3 & 0.16 & 1 \rightarrow 6 & 0.40 \\ 1 \rightarrow 4 & 0.01 & 1 \rightarrow 7 & \sim 0\end{array}$

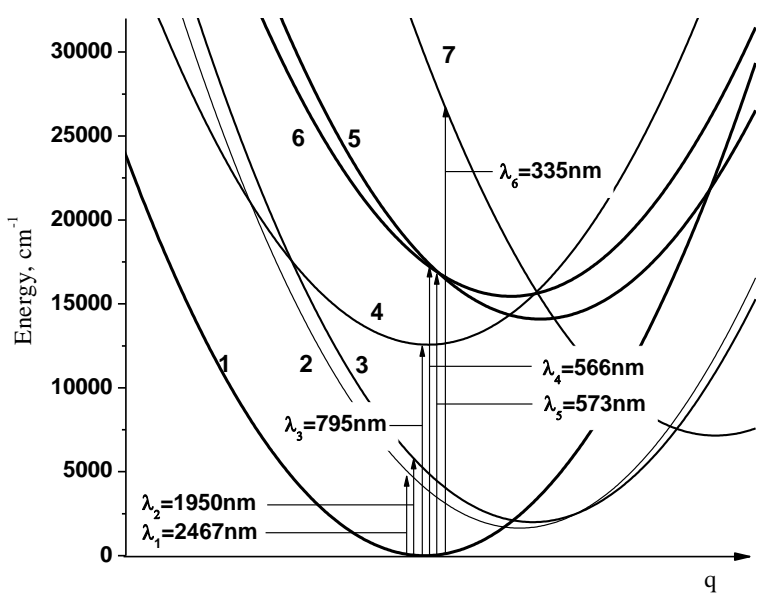

Fig. 12: Adiabatic potentials of the $\mathrm{Mn}^{4+}$ species in the singlemode model, calculated with $G=6.3, \quad B=1070 \mathrm{~cm}^{-1}$, $\hbar \omega_{1}=665 \mathrm{~cm}^{-1}$. The wavelengths $\lambda_{i}$ indicate the maxima of the absorption bands arising on the transitions from the ground adiabatic potential sheet to the excited ones.

The pattern of adiabatic potentials (Fig. 11) shows that the optical transitions of the $\mathrm{Mn}^{4+}$ ions may take place in a wide spectral range from near infrared to violet. At the same time the estimation of the normalized oscillator strengths $f_{1 \rightarrow i}=\overline{\left.\left\langle i\left|\hat{V}_{\text {odd }}^{(1)} \boldsymbol{d}\right| I\right\rangle\right|^{2}} / \sum_{k} \overline{\left.\left\langle k\left|\hat{V}_{\text {odd }}^{(1)} \boldsymbol{d}\right| I\right\rangle\right|^{2}}$

with the aid of Eq. 18 and the following expression for the odd parity crystal field potential (written in the same approximation as Eq. 21)

$V_{\text {odd }}^{M n^{4+}}=A_{11} Y_{1,1}(\theta, \varphi)+A_{1,0} Y_{1,0}(\theta, \varphi)+A_{1,-1} Y_{1,-1}(\theta, \varphi)$

show that the optical transitions from the ground adiabatic potential sheet to the sheets 5 and 6 are most pronounced (Table 9, Fig.11). Thus, the apparent absorption band arising from $\mathrm{Mn}^{4+}$ species is formed mainly by the optical transitions $1 \rightarrow 5$ and $1 \rightarrow 6$. The absorption band arising from $\mathrm{Mn}^{4+}$ species was calculated using the relation $K_{\mathrm{Mn}^{4+}}(\Omega) \sim x_{\mathrm{Mn}^{4+}} \Omega_{\mathrm{Mn}^{4+}}(\Omega)$, where $x_{M n^{4+}}$ is the relative concentration of $\mathrm{Mn}^{4+}$ ions and the form-function $\mathrm{Fnn}_{\mathrm{Mn}^{4+}}(\Omega)$ is determined by Eq. 12 .
Table 10: $\mathrm{x}_{\mathrm{Mn}^{4+}} / x_{\mathrm{Mn}^{3+}}$ Ratios during Activation of MnSZ (2\% $\mathrm{Mn})$ in $\mathrm{O}_{2}$ Determined Using Diffuse Reflectance UV-Vis Spectra (Figure 2) and Calculated Apparent Absorption Spectra in the Visible Range

$\begin{array}{cc}T(\mathrm{~K}) & \beta=x_{\mathrm{Mn}^{++}} / x_{\mathrm{Mn}^{2+}} \\ 373 & 1.33 \\ 523 & 1.47 \\ 623 & 1.5 \\ 723 & 1.6\end{array}$

\section{Determination of the relative concentra- tions of Mn2+, Mn3+ and Mn4+ ions in man- ganese-promoted sulfated zirconia}

Following the considerations presented in Section 2 we simulated the apparent absorption spectra of manganese promoted sulfated zirconia in the wavelength range of $450 \mathrm{~nm}<\lambda<780 \mathrm{~nm}$ using the relation $K(\Omega) \sim x_{\mathrm{Mn}^{3+}} \Omega F_{\mathrm{Mn}^{3+}}(\Omega)+x_{\mathrm{Mn}^{4+}} \Omega F_{\mathrm{Mn}^{4+}}(\Omega)$ . The simulation consisted of two steps. In the first step we calculated the form-functions $\mathrm{F}_{\mathrm{Mn}^{3+}}(\Omega)$ and

$F_{M n}{ }^{4+}(\Omega)$ using Eqs. 11 and 12, and data listed in the tables. In the second step, we determined the ratio $x_{M n^{4+}} / x_{M n^{3+}}$ for a variety of conditions by fitting calculated to experimental spectra. Such fits are shown in Fig. 12 for spectra obtained during activation of manganesepromoted sulfated zirconia in helium flow. At $373 \mathrm{~K}$, the ratio $x_{\mathrm{Mn}^{4+}} / x_{\mathrm{Mn}^{3+}}$ was 1.30 , at $523 \mathrm{~K}$ it was 1.35 , and at $723 \mathrm{~K}$ it reached 1.54 (Table 10). In flowing $\mathrm{O}_{2}$ (Fig. 13), the same trend was observed: in the temperature range 373-723 K the ratio $x_{\mathrm{Mn}^{4+}} / x_{\mathrm{Mn}^{3+}}$ increased from 1.33 to 1.60 (Table 11). The $x_{M n^{4+}} / x_{M n^{3+}}$ values obtained for different temperatures were further used to determine the relative concentrations $x_{\mathrm{Mn}^{2+}}, x_{\mathrm{Mn}^{3+}}, x_{\mathrm{Mn}^{4+}}$ of $\mathrm{Mn}^{2+}, \mathrm{Mn}^{3+}$ and $\mathrm{Mn}^{4+}$ ions, respectively, in the catalyst at various temperatures. For this purpose the following system of three equations was solved:

$$
\begin{aligned}
& 2 x_{M n^{2+}}+3 x_{M n^{3+}}+4 x_{M n^{4+}}=\alpha, \\
& x_{M n^{2+}}+x_{M n^{3+}}+x_{M n^{4+}}=1, \\
& x_{M n^{4+}} / x_{M n^{3+}}=\beta
\end{aligned}
$$

The first equation determines the mean valence $\alpha$ of manganese ions in the catalyst. The second equation represents the normalization condition, and the third equa 


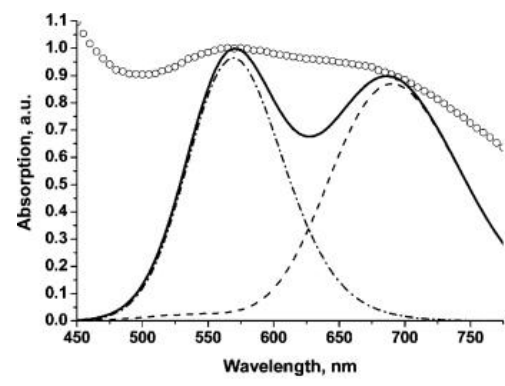

a)

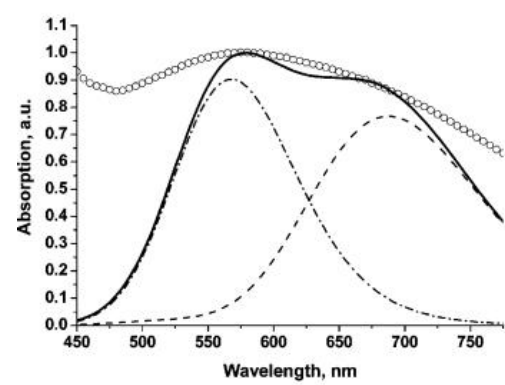

c)

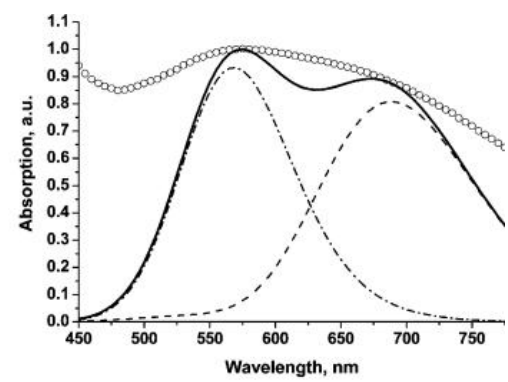

b)

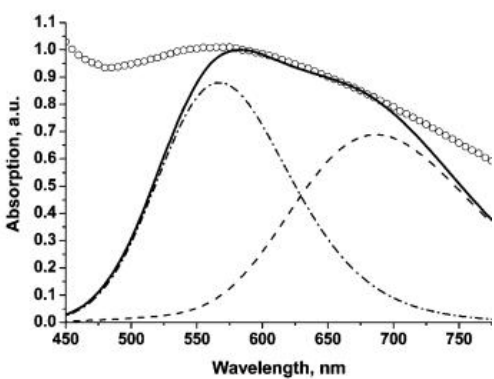

d)

Fig.12: Apparent absorption spectra of MnSZ (2 wt $\% \mathrm{Mn}$ ) in flow of helium (normalized). Circles - experimental data, black line - total calculated spectra, dashed line - contribution from the $\mathrm{Mn}^{3+}$ species to the total band, dot-dashed line - contribution from the $\mathrm{Mn}^{4+}$ species to the total band

$\mathrm{T}=373 \mathrm{~K}: x_{\mathrm{Mn}^{4+}} / x_{\mathrm{Mn}^{3+}}=1.30$; b) $\mathrm{T}=523 \mathrm{~K}: x_{\mathrm{Mn}^{4+}} / x_{\mathrm{Mn}^{3+}}=1.35$;

$\left.\mathrm{T}=623 \mathrm{~K}: x_{M n^{4+}} / x_{M n^{3+}}=1.40 ; \mathrm{d}\right) \mathrm{T}=723 \mathrm{~K}: x_{M n^{4+}} / x_{M n^{3+}}=1.54$.

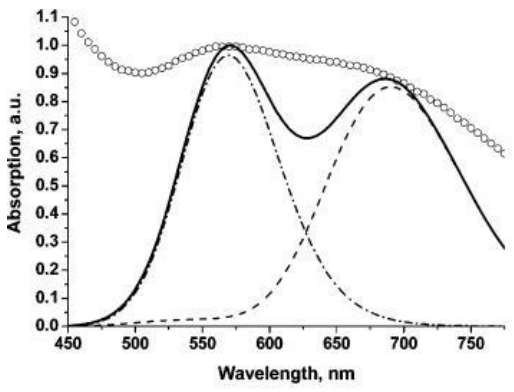

a)

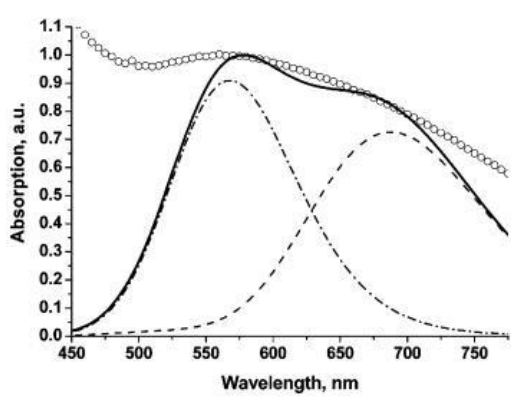

c)

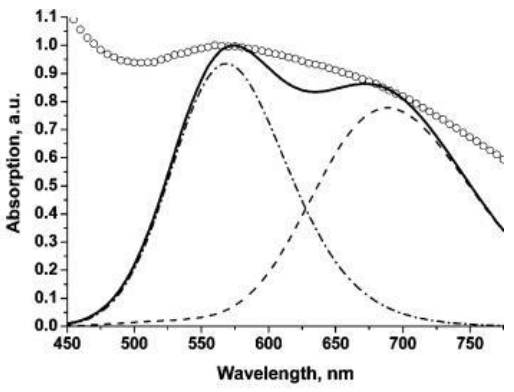

b)

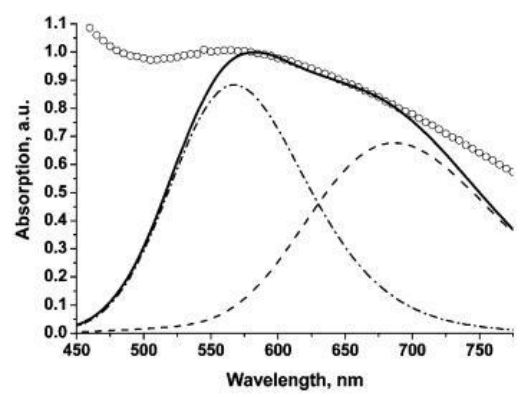

d)

Fig.13: Apparent absorption spectra of the $\mathrm{MnSZ}(2 \mathrm{wt} \% \mathrm{Mn})$ in flow of $\mathrm{O}_{2}$ (normalized). Circles - experimental data, black line - total calculated spectra, dashed line - contribution from the $\mathrm{Mn}^{3+}$ species to the total band, dot-dashed line - contribution from the $\mathrm{Mn}^{4+}$ species to the total band
a) $\mathrm{T}=373 \mathrm{~K}: x_{\mathrm{Mn}^{4+}} / x_{\mathrm{Mn}^{3+}}=1.33$; b) $\mathrm{T}=523 \mathrm{~K}: x_{\mathrm{Mn}^{4+}} / x_{\mathrm{Mn}^{3+}}=1.47$;
c) $\mathrm{T}=623 \mathrm{~K}: x_{M n^{4+}} / x_{M n^{3+}}=1.50 ;$ d) $\mathrm{T}=723 \mathrm{~K}: x_{M n^{4+}} / x_{M n^{3+}}=1.60$. 
tion characterizes the ratio of $x_{\mathrm{Mn}^{3+}}$ and $x_{\mathrm{Mn}^{4+}}$ ions.

To determine the values $x_{M n^{2+}}, x_{M n^{3+}}, x_{M n^{4+}}$ from the system of equations (28), the mean valence $\alpha$ at various temperatures was taken from our preceding work [12], in which equivalently prepared samples were analyzed by XAS under conditions similar to those applied here. The value $\alpha$ varied with the experimental conditions. The determined values $x_{\mathrm{Mn}^{2+}}, x_{\mathrm{Mn}^{3+}}, x_{\mathrm{Mn}^{4+}}$ are given in Table 10

From the data in Table 10 it follows that the relative concentration of $\mathrm{Mn}^{2+}$ ions increases from 0.54 to 0.67 during heating in helium flow, which is in accordance with the temperature behavior of the charge transfer band. The edge of the charge transfer band shifts to shorter wavelengths (or higher energy), indicating an increase in the number of $\mathrm{Mn}^{2+}$ ions. The fraction of $\mathrm{Mn}^{3+}$ ions decreased from 0.20 to 0.13 , which is also in agreement with the CT band behavior. $\mathrm{Mn}^{3+}$ species seem more prone to reduction than $\mathrm{Mn}^{4+}$ species.

XAS data indicate that during heating in $50 \% \mathrm{O}_{2}$ a net reduction occurs [12]. No XAS data and thus no average valence were available for heating in $100 \% \mathrm{O}_{2}$. However, the data in Table 11 indicate that the relative concentration of $\mathrm{Mn}^{4+}$ increases, and the spectra in Fig. 2 demonstrate that also the absolute concentration of $\mathrm{Mn}^{4+}$ increases while that of $\mathrm{Mn}^{3+}$ remains constant, indicating that in $100 \% \mathrm{O}_{2}$, a net oxidation occurs.

\section{Conclusions}

UV-Vis spectra of manganese-doped zirconia were interpreted. Bands at 300-320 nm were assigned to charge transfer from $\mathrm{O}^{2-}$ to $\mathrm{Mn}^{2+}$, to $\mathrm{Mn}^{3+}$, and to $\mathrm{Mn}^{4+}$ ions, with

\section{References}

[1] Lamb, A.B.; Bray, W.C.; Frazer, J.C.W. Ind. Eng. Chem. 1920, 12, 213-221.

[2] Krämer, M.; Schmidt, T.; Stöwe, K.; Maier, W.F. Appl. Catal., A 2006, 302, 257-263.

[3] Nozaki, F.; Sodesawa, T.; Yamamoto, T. J. Catal. 1983, 84, 267-9.

[4] Wöllner, A.; Lange, F.; Schmelz, H.; Knözinger, H. Appl. Catal., A 1993, 94, 181-203.

[5] Keshavaraja, A.; Ramaswamy, A.V. Appl. Catal., B 1996, 8, L1-L7.

[6] Keshavaraja, A.; Ramaswamy, A.V. Chem. Commun. (Cambridge, $U$. K.) 1996, 397-398.

[7] Hsu, C.-Y.; Heimbuch, C.R.; Armes, C.T.; Gates, B.C. J. Chem. Soc., Chem. Commun. 1992 1645-1646.

[8] Lange, F.C.; Cheung, T.-K.; Gates, B.C., Catal. Lett. 1996, 41, 95-99. the wavelength becoming shorter as the manganese valence decreases. The band at $580 \mathrm{~nm}$ mainly arises from the $1 \rightarrow 5,1 \rightarrow 6$ transitions in 8 -coordinated $\mathrm{Mn}^{4+}$ ions, while the band at $680 \mathrm{~nm}$ was assigned to $\mathrm{Mn}^{3+}$ species in trigonally distorted octahedral symmetry. These findings make it possible to re-evaluate contradictory interpretations in the literature.

The crystal field splitting, vibronic interaction and oscillator strength of $\mathrm{Mn}^{3+}$ and $\mathrm{Mn}^{4+}$ ions in their respective environments of $\mathrm{O}^{2-}$ ions were modelled, and the experimental spectra could be well described, using a single phenomenological parameter. With the help of the model, the ratio of $\mathrm{Mn}^{3+}$ to $\mathrm{Mn}^{4+}$ ions in manganese-doped zirconia could be determined from the UV-vis spectra, and with additional knowledge of the average valence from XAS data, the fractions of $\mathrm{Mn}^{2+}, \mathrm{Mn}^{3+}$ and $\mathrm{Mn}^{4+}$ ions could be calculated. $\mathrm{Mn}^{3+}$ is the most redox-active valence inside the zirconia lattice, it is more easily reduced than $\mathrm{Mn}^{4+}$, and $\mathrm{Mn}^{2+}$ is more easily oxidized to $\mathrm{Mn}^{4+}$ than to $\mathrm{Mn}^{3+}$.

\section{Acknowledgement}

Financial support of S.I.K. through DFG, grant 436 MOL 17/1/04, is acknowledged. The authors thank the Max Planck Society for long-term financial support of the project and Giulio Lolli for recording the low-temperature UV-vis spectra.
[9] Lin, C.-H.; Hsu, C.-Y.; J. Chem. Soc., Chem. Comm. 1992, 1479-1480.

[10] Wan, K. T.; Khouw, C. B.; Davis, M. E. J. Catal. 1996, 158, 311-326.

[11] Song, S.X.; Kydd, R.A. Catal. Lett. 1998, 51, 95-100.

[12] Jentoft, R.E.; Hahn, A.H.P.; Jentoft, F.C.; Ressler, T. Phys. Chem. Chem. Phys. 2005, 7, 2830-2838.

[13] Klose, B.S.; Jentoft, F.C.; Schlögl R.; Subbotina, I.R.; Kazansky, V.B., Langmuir, 2005, 21, 10564.

[14] Klose, B.S.; Jentoft, F.C.; Schlögl, R. J. Catal. 2005, 233, 68.

[15] Li, X.; Nagaoka, K.; Simon, L.J.; Olindo, R.; Lercher, J.A.; Hofmann, A.; Sauer, J. J. Am. Chem. Soc. 2005, 127, 16159.

[16] Valigi, M.; Gazzoli, D.; Dragone, R.; Marucci, A.; Mattei, G. J. Mater. Chem. 1996, 6, 403-408.

[17] Ressler, T.; Brock, S.L.; Wong, J.; Suib, S.L. J. Phys. Chem., 1999, 193, 6407-6420 
[18] Jentoft, F.C.; Hahn, A.; Kröhnert, J.; Lorenz, G.; Jentoft, R.E.; Ressler, T.; Wild, U., Schlögl, R.; Hässner, C.; Köhler, K. J. Catal., 2004, 224, 124-137.

[19] Goldberg, D.P.; Telser, J.; Krzystek, J.; Garrido Montalban, A.; Brunel, L.-C.; Barrett, A.G.M.; Hoffman, B.M. J. Am. Chem. Soc. 1997, 119, 8722.

[20] Wallbank, B.; Main, I.G.; Johnson, C.E. J. Electron Spectr. Rel. Phenom. 1974, 5, 259.

[21] Oku, M.; Hirokawa, K.; Ikeda, S. J. Electron Spectr. Rel. Phenom. 1975, 7, 465.

[22] Pratt Jr., G.W.; Coelho, R. Phys. Rev. 1959, 2, 281.

[23] Fernández López, E.; Sánchez Escribano, V.; Resini, C.; Gallardo-Amores, J.M.; Busca, G. Appl. Catal. B: Environmental 2001, 29, 251.

[24] Milella, F.; Gallardo-Amores, J.M.; Baldi, M.; Busca, G. J. Mater. Chem., 1998, 8, 2525.

[25] Sjoerd Kijlstra, W.; Poels, E.K.; Bliek, A.; Weckhuysen, B.M.; Schoonheydt, R.A. J. Phys. Chem. B 1997,101, 309.

[26] Mehra, A.; Venkateswarlu, P. J. Chem. Phys. 1968, 48, 4381.

[27] Geschwind, S.; Kisliuk, P.; Klein, M.P.; Remeika, J.P.; Wood, D.L. Phys. Rev. 1962, 126, 1684.

[28] Holmes, O.G.; McClure, D.S. J. Chem. Phys. 1957, 26, 1686.

[29] McClure, D.S.; J. Chem. Phys. 1962, 36, 2757.

[30] Rajić, N.; Stojaković. D.; Hočevar, S.; Kaučič, V. Zeolites 1993, 13, 384-387.

[31] Cotton, F.A.; Wilkinson, G.; Murillo, C.A.; Bochmann, M. Advanced Inorganic Chemistry, $6^{\text {th }}$ Edition, WileyInterscience: New York, USA, 1999.

[32] Cordischi, D.; Valigi, M.; Gazzoli, D.; Indovina, V. J. Solid State Chem. 1975, 15, 82-88.

[33] Stöcker, H.J. Ann. Chim. 1960, 5, 1459-1502.

[34] Stöcker, J.; Collongues, R. Compt. Red. 1957, 245, 695-697.

[35] Keshavaraja, A.; Ramaswamy, A.V. J. Mater. Res. 1994, 9, $837-840$.

[36] Jentoft, F.C.; Hahn, A.; Kröhnert, J.; Lorenz, G.; Jentoft, R.E.; Ressler, T.; Wild, U.; Schlögl, R.; Hässner, C.; Köhler, K. J. Catal., 2004, 224, 124-137.

[37] Hahn, A.; Ressler, T.; Jentoft, R.E.; Jentoft, F.C. Chem. Commun. 2001, 537-538.

[38] Ciuparu, D.; Ensuque, A.; Shafeev, G.; Bozon-Verduraz, F., J. Mater. Sci. Lett. 2000, 19, 931.

[39] Navío, J. A.; Hidalgo, M. C.; Colón, G.; Botta, S. G.; Litter, M. I. Langmuir 2001, 17, 202 .
[40] Gutiérrez-Alejandre, A.; Ramírez, J.; Busca, G. Catal. Lett. 1998, 56, 29.

[41] Hintze, P. E.; Kjaergaard, H. G.; Vaida, V.; Burkholder, J. B. J. Phys. Chem. A 2003, 1112-1118.

[42] Azzoni, C.B.; Paleari, A. Phys. Rev. B 1991, 44, 6858.

[43] Azzoni, C.B.; Bolis, L.; Paleari, A.; Samoggia, G.; Scardina, F. Phys. Rev.B 1995, 51, 15942.

[44] Sugano, S.; Tanabe, Y.; Kamimura, H. Multiplets of Transition Metal Ions in Crystals, Academic Press: New York and London, USA and U.K., 1970.

[45] Popova, M.N.; Chukalina, E.P.; Malkin, B.Z.; Saikin, S.K. Phys.Rev. B. 2000, 61, 7421.

[46] Klokishner, S.; Melsheimer, J.; Jentoft, F.C.; Schlögl, R. Phys. Chem. Chem. Phys. 2004, 6, 2066.

[47] Klokishner, S.I.; Tsukerblat, B.S.; Reu, O.S.; Palii, A.V.; Ostrovsky, S.M. Chem. Phys. 2005, 316, 83.

[48] Klokishner, S.I.; Tsukerblat, B.S.; Reu, O.S.; Palii, A.V.; Ostrovsky, S.M. Optical Materials 2005, 27, 1445.

[49] Klokishner, S.I.; Reu, O.S.; Ostrovsky, S.M.; Palii, A.V.; Kulyuk, L.L.; Tsukerblat, B.S.; E.Towe, J. Mol. Str. 2007, 838, 133.

[50] Klokishner, S.; Reu, O.; Ostrovsky, S.; Palii, A.; Towe, E. J. Phys.: Condens. Matter 2007, 19, 486213.

[51] Clementi, E.; Roetti, C., At. Data Nucl. Data Tables 1974, 14, 177.

[52] Perlin, Yu.E.; Tsukerblat, B.S. Effects of Vibronic Interactions in the Optical Spectra of Paramagnetic Impurity Ions, Pub. Shtiintsa (Rus.): Kishinev, USSR, 1974; Perlin, Yu.E.; Tsukerblat, B.S. Optical Bands and Polarization of JahnTeller Centers, in: The Dynamical Jahn-Teller Effect in Localized Systems (Eds.: Perlin, Yu.E.; Wagner, M.), vol.7, p.251, Elsevier, 1984.

[53] Li, P.; Chen, I-Wei; Penner-Hahn, J.E., Phys. Rev. B 1993, 48, 10063; 1993, 48, 10074; 1993, 48, 10082.

[54] Stapper, G.; Bernasconi, M.; Nicoloso, N.; Parrinello, M. Phys. Rev. B 1999, 59, 797.

[55] Steele, D.; Fender, B.E.F. J. Phys. C 1974, 7, 1.

[56] Ishizawa, N.; Matsushima, Y. Acta Cryst. B 1999, 55, 726.

[57] Dravid, V.P., Ravikumar, V., Notis, M.R.; Lyman, C.E. J. Am. Ceram. Soc. 1994, 77, 2758.

[58] Lutterotti, L.; Scardi, P. J. Appl. Cryst. JACGA 23, 1990, 246-252. 